\title{
ÁCAROS (ACARI) ASSOCIADOS AOS BESOUROS COPRÓFAGOS (COLEOPTERA: SCARABAEIDAE)
}

\author{
SÉRGIO ROBERTO RODRIGUES \\ Eng. Agrônomo
}

Orientador: Prof. Dr. LUÍS CARLOS MARCHINI

Tese apresentada à Escola Superior de Agricultura "Luiz de Queiroz", Universidade de São Paulo, para a obtenção do título de Doutor em Ciências, Área de Concentração: Entomologia.

PIRACICABA

Estado de São Paulo, Brasil

Setembro - 2000 


\title{
Dados Internacionais de Catalogação na Publicação (CIP) DIVISẢO DE BIBLIOTECA E DOCUMENTAÇĀO - Campus "Luiz de Queiroz"/USP
}

\author{
Rodrigues, Sérgio Roberto \\ Ácaros (Acari) associados aos besouros coprófagos (Coleoptera: Scarabaeidae) / \\ Sérgio Roberto Rodrigues. - - Piracicaba, 2000. \\ $77 \mathrm{p}$.
}

Tese (doutorado) - Escola Superior de Agricultura Luiz de Queiroz, 2000.

Bibliografia.

1. Ácaro 2. Besouro-copráfago 3. Ecologia 4. Forésia I. Título

CDD 632.7649

Permitida a cónia total ou parcial deste documento, desde que citala a fonte = O autod? 
Aos meus pais,

José e Neusa

DEDICO

A minha esposa Andréa,

e ao nosso filho Daniel,

\section{OFEREÇO}




\section{AGRADECIMENTOS}

Ao Prof. Dr. Luís Carlos Marchini (Departamento de Entomologia, Fitopatologia e Zoologia Agrícola da Escola Superior de Agricultura "Luiz de Queiroz" - ESALQ, Universidade de São Paulo - USP), pela orientação, amizade e constante apoio durante a realização do curso.

À Universidade Estadual de Mato Grosso do Sul (UEMS), pelo auxílio concedido.

Aos Professores do Departamento de Entomologia, Fitopatologia e Zoologia, ESALQ-USP, pelo convivio e ensinamentos.

Ao Dr. Leonardo Delgado (Setor de Ecologia, Xalapa, Veracruz, Mexico) pela identificação de besouros coprófagos dos gêneros Onthophagus e Eurysternus.

Ao Eng. Agrônomo Fernando Z. Vaz-de-Mello (Setor de Ecologia, Universidade Federal de Viçosa, Viçosa, MG), pela identificação de algumas espécies de besouros coprófagos.

Ao Dr. Ernst Ebermann (Institute of Zoology, Karl-Franzens-University, Universitaetsplatz, Graz, Austria) pela identificação dos ácaros da família Scutacaridae e pela doação de artigos científicos sobre essa família.

Ao Dr. Bruce R. Halliday (CSIRO, Division of Entomology, Canberra, Austrália), pela identificação de ácaros da família Macrochelidae e Parasitidae.

A Dra. Márcia Cristina Mendes (Instituto Biológico, Seção de Parasitoses, São Paulo) pela identificação de ácaros da família Macrochelidae. 
A MSc. Karin Camerik (Department of Zoology, University of the Witwatersrand, Johannesburg, South Africa) pela identificação de ácaros da família Pygmephoridae e pela doação de artigos científicos sobre essa família.

Ao Dr. Ronald Ochoa (Systematic Entomology Laboratory, USDA, Beltsville, Maryland) pela doação de artigos científicos sobre a família Pygmephoridae.

Ao Dr. Alex Fain (Institut Royal des Sciences Naturelles de Belgique, Bruxelles, Bélgica) pela identificação de ácaros da família Acaridae.

Ao prof. Dr. Gilberto de Moraes pelos ensinamentos sobre ácaros durante o curso de Acarologia Agrícola.

Ao Conselho Nacional de Desenvolvimento Científico e Tecnológico (CNPq) pela concessão da bolsa de doutoramento.

Ao Dr. Jairo João Carbonari (EMPAER, Quaraí/RS) pela amizade e valiosa ajuda nos trabalhos de campo.

Ao MSc. Vanderlei Doniseti Acássio dos Reis e MSc. Miguel Angel Ruiz Diaz Villalba pela amizade e valiosa ajuda nos trabalhos de campo.

Aos Zootecnistas Egínia Mara Leite Mendes Fialho, Cilene da Silva Sanches e Anderson Cezar Belmonte Gonçalves, que quando estagiários do curso de Zootecnia em Aquidauana/MS, deram valiosa colaboração nos trabalhos de campo. 


\section{SUMÁRIO}

Página

RESUMO

vii

SUMMARY

viii

1 INTRODUÇÃO

2 REVISÃO DE LITERATURA ................................................................

2.1 Ácaros associados aos besouros coprófagos ............................................... 3

2.2 Ácaros foréticos e parasitos de besouros coprófagos

3 ÁCAROS (ACARI) ASSOCIADOS AOS BESOUROS COPRÓFAGOS (COLEOPTERA: SCARABAEIDAE). FAMÍLIA MACROCHELIDAE (MESOSTIGMATA)

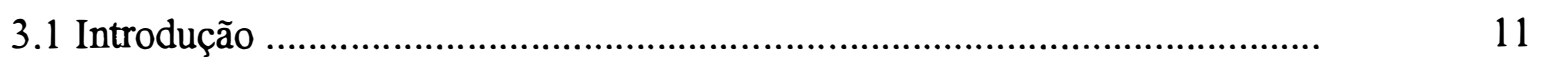

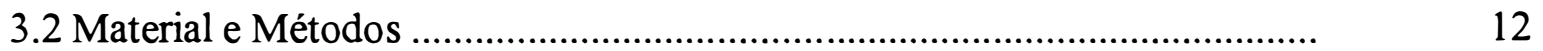

3.2.1 Coleta de besouros coprófagos e extração de ácaros ................................ 12

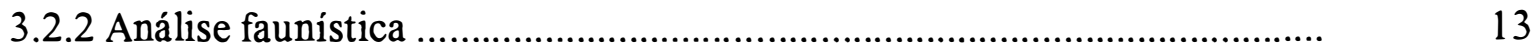

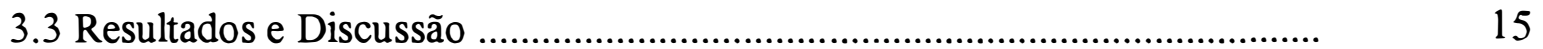

4 ÁCAROS (ACARI) ASSOCIADOS AOS BESOUROS COPRÓFAGOS (COLEOPTERA: SCARABAEIDAE). FAMÍLIAS SCUTACARIDAE E PYGMEPHORIDAE (HETEROSTIGMATA) ...................................... 30

4.1 Introdução ................................................................................. $\quad 30$

4.2 Material e Métodos ............................................................................ 31

4.2.1 Coleta de besouros coprófagos e extração de ácaros ................................ 31

4.3 Resultados e Discussão ..............................................................................

4.3.1 Família Scutacaridae ........................................................................

4.3.2 Família Pygmephoridae .................................................................. 36 
5 ÁCAROS (ACARI) ASSOCIADOS AOS BESOUROS COPRÓFAGOS Página (COLEOPTERA: SCARABAEIDAE). FAMILIAS EVIPHIDIDAE; PARASITIDAE, LAELAPIDAE, PACHYLAELAPIDAE E UROPODIDAE (MESOSTIGMATA), ACARIDAE E ANOETIDAE (ASTIGMATA)

5.1 Introdução

5.2 Material e Métodos

5.2.1 Coleta de besouros coprófagos e extração de ácaros

5.3 Resultados e Discussão 45

6 CONCLUSÕES 54

REFERÊNCIAS BIBLIOGRÁFICAS 55 


\title{
ÁCAROS (ACARI) ASSOCIADOS AOS BESOUROS COPRÓFAGOS (COLEOPTERA: SCARABAEIDAE)
}

\author{
Autor: SÉRGIO ROBERTO RODRIGUES \\ Orientador: Prof. Dr. LUÍS CARLOS MARCHINI
}

\section{RESUMO}

Vários são os trabalhos na literatura internacional que relacionam os ácaros que aparecem associados aos besouros coprófagos, como os ácaros das famílias Macrochelidae, Parasitidae, Eviphididae, Uropodidae entre outras. Com o objetivo de se obter maiores informações sobre os ácaros no Brasil, realizou-se a coleta de besouros coprófagos em áreas de pastagem nos municípios de Piracicaba/SP, Aquidauana/MS e Capão do Leão/RS, para em seguida extrair os ácaros destes e montar lâminas para sua identificação. Na família Macrochelidae as espécies de ácaros encontradas foram Glyptholaspis confusa, Macrocheles merdarius, M. mammifer, M. subbadius, M. insignitus, $M$ roquensis, $M$. robustulus, além de quatro espécies do gênero Macrocheles não identificadas. Na família Scutacaridae as espécies encontradas foram Pygmodispus bicornutus, Scutacarus longitarsus e Scutacarus sp. Na familia Pygmephoridae as espécies encontradas foram Elattoma sp1, Elattoma sp2, Bakerdania sp1, Bakerdania $\mathrm{sp} 2$, Elattosoma sp, Pediculaster sp near brasiliensis e Sicilipes sp. Na família Parasitidae as espécies encontradas foram Parasitus spl, Parasitus sp2 e Parasitus sp3. Na família Acaridae a espécie encontrada foi Sancassania sp near chelone. Foram coletados ainda ácaros das famílias Uropodidae, Eviphididae, Laelapidae, Pachylaelapidae e Anoetidae (=Histiotomatidae). Vários são os locais onde os ácaros foram encontrados nos besouros coprófagos, como na base dos olhos compostos, antenas, na região gular, na membrana intersegmental entre o pterotórax e protórax, sob os élitros, nos pêlos das pernas e no abdome. Os ácaros encontrados aparecem associados aos besouros praticando forese. 


\title{
MITES (ACARI) ASSOCIATED WITH DUNG BEETLES (COLEOPTERA: SCARABAEIDAE)
}

\author{
Author: SÉRGIO ROBERTO RODRIGUES \\ Adviser: Prof. Dr. LUÍS CARLOS MARCHINI
}

\section{SUMMARY}

There are many papers relating mites associated with dung beetles, mainly those mites of the families Macrochelidae, Parasitidae, Eviphididae and Uropodidae. In order to enrich the Brazillian literature on such mites, a collecting of dung beetles in pasture areas was performed in the counties of Piracicaba, State of São Paulo, Aquidauana, State of Mato Grosso do Sul, and Capão of Leão, State of Rio Grande do Sul. The mites were then taken from the different body parts of the beetles and mounted on slides for identification. The following species, and respective families, were found: Glyptholaspis confusa, Macrocheles merdarius, M. mammifer, M. subbadius, M. insignitus, M. roquensis, $M$. robustulus and four unidentified species of the genus Macrocheles, family Macrochelidae; Pygmodispus bicornutus, Scutacarus longitarsus and Scutacarus sp, family Scutacaridae; Elattoma sp1, Elattoma sp2, Bakerdania sp1, Bakerdania sp2, Elattosoma sp, Pediculaster sp near brasiliensis, and Sicilipes sp, family Pygmephoridae; Parasitus sp1, Parasitus sp2, Parasitus sp3, family Parasitidae; Sancassania sp near chelone, family Acaridae; plus unidentified species of the families Uropodidae, Eviphididae, Laelapidae, Pachylaelapidae and Anoetidae (=Histiotomatidae). Mites were found in the following body sites of the dung beetles: base of compound eyes and antennae, gular plate, intersegmental membrane between pterothorax and prothorax, under the elytra, leg hairs, and abdomen. Phoresy is the relationship between mites and dung beetles. 


\section{INTRODUÇÃO}

Os ácaros apresentam uma grande diversidade em sua morfologia, e em muitos casos paralelos com características de comportamento, onde a especialização em hábito e habitat freqüentemente acompanha especialização em estrutura. Por isso, é essencial o conhecimento dos hábitos e habitats, para identificação e classificação (Krantz, 1975; Flechtmann, 1989).

Podemos reconhecer basicamente duas categorias de ácaros, a de vida livre e a de parasitas. Entre as formas de vida livre encontramos ácaros predadores, fitófagos, micófagos, coprófagos e os foréticos que usam de outros artrópodos como meio de dispersão (Krantz, 1975; Flechtmann,1989).

Dentre os ácaros de vida livre e os parasitos, estão aqueles que podem predar insetos, como os ácaros da família Macrochelidae, Ascidae, Parasitidae entre outras. Os ácaros foréticos de insetos, normalmente são deutoninfas e adultos de algumas fa mílias como Laelapidae, Rhodacaridae, Macrochelidae entre outras. Os ácaros podem ainda serem ectoparasitos de insetos como espécies das famílias Erythraeidae, Smaridiidae, Pyemotidae, etc, e endoparasitos de insetos como espécies das famílias, Tarsonemidae, Podapolipidae etc. (Krantz, 1975).

Os ácaros podem estar associados a várias ordens de insetos como verificado em Thysanoptera (Hoy \& Glenister, 1991), Coleoptera (Gordh \& Wills, 1989; Husband \& Baker, 1992; Naskrecki \& Colwell, 1995; Fain et al., 1995b), Lepidoptera (Mcneil \& Treat, 1992; Hoschele \& Tanigoshi, 1993), Diptera (Pugh et al., 1991; Wendt et al., 1992), Hymenoptera (Flechtmann, 1980; Wendt et al., 1992; Viana, 1994), Odonata (Mcneil \& Treat, 1992), Orthoptera (Husband \& Baker, 1992), entre outras. 
Os besouros coprófagos, pertencem à família Scarabaeidae, da qual estima-se existirem mais de 20 mil espécies no mundo (Rodrigues, 1985; Fincher 1991). São importantes agentes de remoção e incorporação de massas fecais em áreas de pastagem (Calafiori \& Alves, 1980), podendo com sua atividade de remoção alterar as propriedades físico-químicas do solo (Calafiori, 1979; Brussaard \& Runia, 1984; Kalisz \& Stone, 1984), auxiliando no melhor desenvolvimento de plantas (Alves \& Nakano, 1977), controlando nematóides gastrointestinais (Bryan, 1973; 1976) e moscas que nas massas se desenvolvem (Ridsdill-Smith, 1988; Doube et al., 1988).

Várias são as espécies de ácaros que podem estar associados a esse importante grupo de besouros (Berlese, 1910, 1913; Krantz, 1965; Masan, 1994). Alguns ácaros, podem ser parasitos dos besouros (Husband, 1989) ou apenas foréticos (Costa, 1967; Krantz, 1991), enquanto que outros podem ser importantes predadores de ovos e larvas de moscas de importância veterinária (Halliday \& Holm, 1987; Roth et al., 1988).

Vários são os trabalhos que relatam a fauna de besouros coprófagos ocorrentes em regiões do Brasil (D’ Olsoufieff, 1924; Luederwaldt, 1929, 1931; Pessoa, 1934, 1935; Paulian, 1939; Lange, 1947; Link, 1976; Alves, 1977; Jessop, 1985; Stumpf, 1986; Klein, 1989; Ferreira \& Galileu, 1993; Flechtmann et al., 1995b; Louzada \& Lopes, 1997; Rodrigues \& Marchini, 1998; Vaz-de-Mello, 1999; Koller et al., 1999), entretanto, pouco se conhece sobre os ácaros associados a esse grupo de besouros. 


\section{REVISÃO DE LITERATURA}

\section{1 Ácaros associados aos besouros coprófagos}

A associação de ácaros com besouros coprófagos é conhecida a vários anos, sendo que muitas espécies de ácaros foram descritas a partir da coleta de besouros.

Berlese $(1910,1917)$ descreveu várias espécies de ácaros associados a besouros coprófagos, como:

- na família Macrochelidae descreveu várias espécies dos gêneros Macrocheles, Holostaspella, Holocelaeno e Holostaspis;

- na família Pachylaelapidae descreveu ácaros dos gêneros Pachylaelaps e Megalolaelaps;

- na família Eviphididae descreveu ácaros do gênero Copriphis;

- ninfas de Coleoglyphus fuscipes (Acaridae) obtido de Copris hamadryas também foi descrito.

Berlese $(1911,1913)$ descreveu espécies de ácaros da família Eviphididae associados a besouros coprófagos como Copriphis (Peletiphis) insignitus que foi coletado de Gymnopleurus pillularius. Copriphis elongatus e Copriphis (Peletiphis) dermanyssoides foram descritos a partir de sua coleta de Ateuchus cuvieiri. Copriphis (Peletiphis) crinitus foi descrito depois de extraído de Ateuchus semipunctato e Copriphis (Peletiphis) equestris foi descrito a partir de sua coleta em Geotrupes stercorarii. Na família Podapolipidae, Tarsopolipus corrugatus foi descrito após ser coletado em Ateuchus semipunctato. Na família Pygmephoridae, Pygmephorus stercoricola foi descrito depois de obtido de Geotrupis hypocritae.

A associação de ácaros com besouros também foi verificada por Krantz (1967), que encontrou um total de 40 espécies de ácaros da família Macrochelidae do gênero 
Holocelaeno em besouros coprófagos. Os ácaros foram coletados nas regiões gular, coxal e ocasionalmente sob os élitros dos besouros.

Foram encontradas 18 espécies de Macrochelidae do gênero Neopodocinum habitando regiões tropicais, subtropicais e temperadas da Ásia, África e Europa, em associação a besouros coprófagos da família Scarabaeidae (Krantz, 1965).

Filipponi \& Pegazzano (1967) revisaram o gênero Holostaspella (Macrochelidae) e verificaram que algumas espécies desse gênero mantêm associações com besouros coprófagos. Fêmeas de Holostaspella caelata, por exemplo, foram coletadas de Heliocopris hamadrias e Holostaspella foai foi encontrado em Copris molossus.

Costa (1967) estudando três ácaros do complexo Macrocheles pisentii, verificou que $M$. parapisentii estava associado com Scarabaeus puncticollis, Macrocheles cristati com Scarabaeus cristatus e Macrocheles saceri com Scarabaeus sacer.

Em revisão realizada por Halffter \& Matthews (1971), foram observadas várias famílias e gêneros de ácaros associados a besouros coprófagos. Na sub ordem Astigmata encontraram nas famílias Anoetidae (Anoetoglyphus, Anoetis e Histiostoma), Canestrinidae (Grandiella e Coleopterophagus) e na família Olafseniidae (Tyroglyphus). Na sub ordem Prostigmata encontraram nas famílias Podapolipidae (Tarsopolipus) e Pyemotidae (Pavania). Na sub ordem Mesostigmata encontraram nas famílias Eviphididae (Alliphis, Eviphis, Pelethiphis e Scarabaspis), Laelapidae (Cosmetolaelaps), Macrochelidae (Andrholaspis, Coleolaelaps, Glyphtholaspis, Holocelaeno, Holotaspella, Macrocheles e Neopodocinum), Pachylaelapidae (Ochodellus, Pachylaelaps, Pachyseius e Zygoseius), Parasitidae (Gamasodes e Parasitus) e na família Uropodidae (Uropoda e Pseudouropoda).

Flechtmann \& Alves (1976), coletaram espécies de besouros coprófagos e estudaram os ácaros associados. Em Dichotomius camporum, Dichotomius crinicollis, Diabrocticas mimas e Phanaeus ensifer encontraram ninfas de Uropodidae; em Dichotomius longiceps encontraram "hypopus" de Acaridae e em Phanaeus jasius e Phanaeus splendidulus encontraram fềmeas de Macrochelidae. 
Krantz (1981) descreveu as espécies Macrocheles eurygaster e M. peregrinus. Para M. eurygaster relacionou 14 espécies de besouros coprófagos como hospedeiros (Catharsius tricornutus, Colobopterus maculicollis, Copris elphenor, C. fallaciosus, Euoniticellus intermedius, Garreta malleolus, Liatongus militaris, Metacatharsius sp., Onitis alexis, O. aygulus, O. caffer, O. deceptor, O. viridulus e O. westermanni), e para M. peregrinus relacionou 43 espécies de besouros coprófagos hospedeiros (Allogymnopleurus thalassinus, Catharsius tricormutus, Chironitis scabrosus, $C$. spicticollis, Chironitis sp., Colobopterus maculicollis, Colobopterus sp., Copris anceus, C. elphenor, C. fallaciosus, C. laioides, Euoniticellus africanus, E. intermedius, E. triangulatus, Garreta malleolus, Heliocopris andersoni, Kheper nigreneous, Liatongus militaris, Onitis alexis, $O$. aygulus, $O$. caffer, O. deceptor, O. picticollis, $O$. viridulus, $O$. westermanni, Onthophagus aciculatus, O. alcyon, O. auriceps, O. binodis, O. brucei, O. confusus, O. gazella, O. minutus, O. tersidorsus, Onthophagus sp1, Onthophagus sp2, Phalops smaragdinus, Sarophorus costatus, Scarabaeus goryi, S. rugosus, Sisyphus fortuitus, S. rubrus e $S$. spinipes).

Wallace \& Holm (1985) coletaram durante cinco anos besouros coprófagos e avaliaram a fauna de ácaros associados. Encontraram quatro espécies de ácaros dominantes (Macrocheles glaber, M. merdarius, Parasitus coleoptratorum e P. fimetorum). O número de $M$. glaber coletado variou durante o ano, sendo em maior quantidade no mês de dezembro. Macrocheles merdarius foi coletado em pequena quantidade, sendo mais abundante nos meses de abril e maio. Parasitus coleoptratorum tem atividade maior nos meses da primavera (setembro) e verão (dezembro) e $P$. fimetorum é mais abundante na primavera (setembro) e outono (abril e maio) e decresce sua população de dezembro a fevereiro.

Wallace (1986) analisou os ácaros associados a um total de 19.000 besouros coprófagos, sendo 165 espécies da tribo Onthophagini, 22 da Coprini e 88 espécies da tribo Scarabaeini. Macrocheles (near) glaber foi encontrado nos seguintes besouros coprófagos: Onthophagus australis, O. capella, O. dunning, O. granulatus, $O$. pentacanthus, O. mniszechi e Aphodius tasmaniae. Macrocheles peregrinus foi 
encontrado nos seguintes hospedeiros: Euoniticellus intermedius, Onthophagus gazella, Onthophagus parvus, Onitis alexis e Sisyphus spinipes. Macrocheles kraepelini foi coletado em Onthophagus laminatus, Coptodactyla ducalis e Pachylister chinensis. Macrocheles merdarius foi coletado em Onthophagus atrox, O. auritus, O. australis, $O$. capitosus, $O$. consentaneus, $O$. conspicus, $O$. cuniculus, $O$. dandalu, O. dummal, $O$. dunning, O. ferox, O. fissiceps, O. flavoapicalis, O. gangalu, O. glabratus $O$. gazella, $O$. haagi, O. incanus, O. jangga, O. laminatus, O. latro, O. mjobergi, O. mniszechi, O. muticus, O. nodulifer, O. parrumbal, O. parvus, O. pentacanthus, O. pexatus, $O$. pugnacior, $O$. queenslandicus, $O$. quinquetuberculatus, $O$. rubrimaculatus, $O$. sagittarius, O. semimetallicus, O. sloanei, O. taurus, O. villosus, Coptodactyla depressa, C. glabricollis, C. lesnei, C. mostrosa, Notopedaria tuberculata, Lepanus palumensis, Aphodius pseudolividus, A. tasmaniae, Euoniticellus intermedius e Liatongus militaris. Macrocheles peniculatus foi encontrado em Onthophagus pentacanthus, O. jangga, O. gazella, O. quinquetuberculatus e Liatongus militaris. Macrocheles robustulus foi encontrado em Onthophagus granulatus e Aphodius tasmaniae. Macrocheles mammifer foi coletado em Onthophagus laminatus. Macrocheles novaezelandiae foi coletado em Onthophagus pugnax e Amphistomus trispiculatus. Macrocheles krantzi foi coletado em Onthophagus nodulifer e $O$. laminatus.

Masan (1994) encontrou várias espécies de ácaros da família Eviphididae associados com algumas espécies de besouros coprófagos e necrófagos: Acamaphis equestris foi encontrado apenas em Geotrupes spiniger; Scarabacariphis grandisternalis foi coletado em Onthophagus fracticornis; Alliphis necrophilus foi coletado em Nicrophorus humator e N. vespillo; Alliphis phoreticus foi coletado em Geotrupes spiniger, Copris lunaris, Oniticellus fulvus, Onthophagus taurus e Aphodius rufipes; Alliphis rotundianalis foi coletado em Onthophagus gibbulus, Geotrupes vernalis, Geotrupes spiniger, Copris lunaris, Onthophagus fracticornis e Aphodius fossor e Pelethipis opacus foi coletado em Copris lunaris. 
Ácaros da família Uropodidae podem estar associados aos besouros coprófagos. Wisniewski \& Hirschmann (1996) encontraram as deutoninfas: Uropoda afghanica associado com Homalocopris tmolus; Uropoda americana associada com Copris sp; $U$. mediterranea associada com Copris hispanicus e $U$. shanghaica com um besouro coprófago não identificado.

Os ácaros associados aos besouros coprófagos podem manter, não apenas uma associação com os adultos, mas também com a fase imatura dos mesmos.

Costa (1969) estudou os ácaros associados com Copris hispanus. Quando o besouro constrói esferas de nidificação (local de oviposição e de desenvolvimento), os estágios imaturos de Parasitus copridis (Parasitidae) podem permanecer no seu interior. Nesse caso os ácaros permanecem dentro da esfera e não se alimentam, ou podem se alimentar de exudatos liberados pela larva em desenvolvimento. Em tal situação o ácaro permanece protegido dentro da esfera de fezes, e não fica exposto aos meses de verão árido. Em esferas de nidificação de $C$. hispanus foram encontradas também várias deutoninfas de Neopodocinum caputmedusae (Macrochelidae).

Os ácaros além de utilizarem os exudatos liberados pelas larvas para alimentação, podem no momento em que as larvas dos besouros realizam a ecdise, se alimentar dos fluídos presentes nos restos da velha exúvia, segundo Móron

\section{2 Ácaros foréticos e parasitos de besouros coprófagos}

A forese é um fenômeno no qual um animal, procura ativamente em todas as direções prender-se a um outro animal por um tempo limitado. A dispersão forética é vital para os ácaros (Houck \& O'connor, 1991; Athias-Binche et al., 1993).

A forese pode ser ocasional, facultativa ou obrigatória. A forese obrigatória é sasonal ou cíclica e ocorre quando a sobrevivência da espécie forética depende do ciclo de vida do hospedeiro. A forese cíclica é mais observada em casos de alta associação específica, no qual os ácaros habitam especificamente o ninho do hospedeiro. Esse é o

\footnotetext{
${ }^{1}$ Móron, M. A. Comunicação pessoal, 1999.
} 
caso de ácaros foréticos sobre o besouro escavador Necrophorus (Athias-Binche ${ }^{2}$, citado por Athias-Binche et al., 1993).

Algumas espécies de Macrocheles podem apresentar comportamento de isolamento forético. Krantz (1991) estudando o comportamento de M. pisentii em cinco espécies de besouros coprófagos do gênero Scarabaeus (Coleoptera, Scarabaeidae), verficou-se que essa espécie de ácaro é mais associado com $S$. semipunctatum, mas em testes de atratividade em arenas, observou que outras espécies de Scarabaeus podem atrair esse ácaro, provavelmente devido a liberação de cairomônios.

Na Família Macrochelidae o gênero Holocelaeno apresenta associação apenas forética com os besouros coprófagos. Mais de uma espécie do gênero Holocelaeno pode estar associado com uma simples espécie de Scarabaeidae (o que é denominado de múltipla forese) ou uma simples espécie de Holocelaeno pode ser conduzido por mais do que uma espécie de besouro hospedeiro (forese não específica) Krantz (1967).

Espécies de Macrochelidae do gênero Neopodocinum são encontrados em associação com besouros coprófagos da família Scarabaeidae. A associação entre esses parece ser puramente forética (Krantz, 1965).

Takaku (1994) encontrou Holostaspella caelata (Macrochelidae) associado com Copris ochus. $\mathrm{O}$ autor discute que não apenas o relacionamento forético existe entre esse ácaro e o besouro coprófago, mas alguma outra associação, que ainda é desconhecida.

Nos ácaros que realizam forese sobre os besouros, algumas alterações morfológicas foram observadas, quando comparados com ácaros que não realizam forese.

Costa (1969) verificou em esferas de nidificação de Copris hispanus várias deutoninfas de Neopodocinum caputmedusae (Macrochelidae). As deutoninfas presentes dentro das esferas de nidificação são morfologicamente diferentes de deutoninfas que foram coletadas diretamente de adultos de $C$. hispanus. Elas são de formato globular,

\footnotetext{
${ }^{2}$ Athias-Binche, F. La phorésie chez les Acariens Uropodides (Anactinotriches), une stratégie écologique originale. Acta Oecologica. (52):119-133, 1984.
} 
fracamente esclerotizadas e possuem curtas setas no escudo dorsal, apresentando portanto diferenças morfológicas, cujas causas, entretanto, não são discutidas pelo autor.

Walter \& Krantz (1992) estudaram espécies de Macrocheles do complexo scutatus e verificaram que os ácaros foréticos sobre besouros Scarabaeini freqüentemente exibem uma forte redução na ornamentação no escudo ventral e diminuição na esclerotização (exceção para $M$. natalensis). As razões para essas reduções não são claras, mas podem estar relacionados com a sua biologia. A esclerotização providencia uma medida de proteção em um habitat altamente competitivo, e quando escapam da competição através de isolação é possível que façam retenção da alta esclerotização que não mais é necessária. Outra possível explicação para a redução da esclerotização seria a dos ácaros escaparem da competição colonizando rapidamente a fonte de alimento. Para isso se fixam nos besouros, que colonizam fezes recém excretadas pelos bovinos, e que são também colonizadas por moscas que ovipositam nas fezes, providenciando um ambiente farto em alimento para os ácaros, onde encontram pequena competição por alimento em uma massa fecal recém-excretada. Outras espécies de Macrocheles que têm associação com Scarabaeini, como o grupo glaber, têm esclerotização clara e mínima ornamentação.

Krantz \& Royce (1992) estudaram estágios imaturos de Macrocheles mycotrupetes e verificaram a ausência de um dente bidentado no dígito móvel das cheliceras das fêmeas e a deficiência no número de sensilos tarsais. Ambas características podem ter um significado na evolução da forese em M. mycotrupetes.

$\mathrm{O}$ parasitismo de ácaros sobre os besouros coprófagos também pode ocorrer. $\mathrm{Na}$ família Podapolipidae os ácaros do gênero Tarsopolipus permanecem sob os élitros dos besouros coprófagos e se comportam como parasitos. Husband (1989) cita: Tarsopolipus hallidayi encontrado em Scarabaeus sp e em Kheper lamarcki; Tarsopolipus bisetalus encontrado em Scarabaeus convexus e Scarabaeus gangeticus, e T. massai encontrado em Scarabaeus semipunctatus. 
Ramaraju \& Mohanasundaram (1996) encontraram a espécie Tarsopolipus ramakrishnai sob os élitros de Scarabaeus brahminus, realizando um possível parasitismo no besouro, enquanto, Husband \& Kurosa $(1993,1995)$ encontraram várias espécies de ácaros da família Podapolipidae, praticando parasitismo sobre besouros fitófagos da família Scarabaeidae. 


\section{3 ÁCAROS (ACARI) ASSOCIADOS AOS BESOUROS COPRÓFAGOS (COLEOPTERA: SCARABAEIDAE). FAMÍLIA MACROCHELIDAE (MESOSTIGMATA).}

\subsection{Introdução}

$\mathrm{Na}$ família Macrochelidae foram descritas cerca de 400 espécies, sendo que o provável número de espécies é superior a 2.000 (Krantz, 1998). Nessa família, os ácaros podem ocorrer em fezes de animais domésticos, além de restos de animais e vegetais em decomposição (Mattos, 1992; Lizaso et al., 1992; Schelvis, 1994; Lizaso \& Mendes, 1994; Nawar, 1995), onde predam estágios imaturos de moscas que nestes ambientes se desenvolvem (Halliday \& Holm, 1987; Geden \& Axtell, 1988; Roth et al., 1988; Geden et al., 1990). Podem também, viver associados com pequenos mamíferos (Krantz, 1983; Adis \& Krantz, 1985; Krantz \& Whitaker Jr, 1988).

Vários Macrochelidae aparecem associados com diferentes grupos de insetos, podendo praticar forese sobre estes (Pereira \& Castro, 1947; Farish \& Axtell, 1971; Moser \& Roton, 1971; Flechtmann \& Alves, 1976; Richards \& Richards, 1977; Samsinák \& Daniel, 1978; Stephen \& Kinn, 1980; Ho, 1990; Poprawski \& Yule, 1992; Fain et al., 1995); alguns são ainda ectoparasitos de invertebrados (Polak, 1996), ou também podem praticar canibalismo (Oliver Jr. \& Krantz, 1963). Em algumas espécies, são conhecidos os seus aspectos biológicos e ecológicos (Costa, 1966, 1967; Cicolani, 1980; Krantz \& Royce, 1994).

Grande número de Macrochelidae são encontrados associados com besouros coprófagos (Berlese, 1910, 1918; Krantz, 1965, 1967; Filipponi \& Pegazzano, 1967; Costa, 1969; Krantz \& Mellott, 1972; Wallace \& Holm, 1985; Takaku 1994), entretanto, 
no Brasil pouco se conhece sobre a fauna associada a esse grupo de besouros. Portanto, o presente trabalho teve por objetivo conhecer as espécies de ácaros dessa família, que ocorrem associados aos besouros coprófagos em área de pastagem.

\subsection{Material e Métodos}

\subsubsection{Coleta de besouros coprófagos e extração de ácaros}

Para realizar a coleta de besouros coprófagos foram utilizadas 4 armadilhas "pitfall" iscadas com massa fecal fresca de bovinos, instaladas em áreas de pastagem na Universidade de São Paulo (ESALQ/USP) em Piracicaba/SP, e na Universidade Estadual de Mato Grosso do Sul (UEMS), no município de Aquidauana/MS.

$\mathrm{O}$ uso de armadilhas "pitfall" tem sido empregada em estudos onde avalia-se a distribuição e o comportamento populacional de besouros coprófagos (Lobo et al., 1988). Ela consiste de um tripé de metal com cerca de $28 \mathrm{~cm}$ de altura, ao qual dependura-se um volume de cerca de $700 \mathrm{ml}$ de massa fecal fresca de bovino, envolta em tecido de voal. Imediatamente sob a massa, são colocados dois copos plásticos, um encaixado dentro do outro, de $350 \mathrm{ml}$ de volume, enterrados ao nível do solo, e preenchido com água e detergente.

Após 24 horas da instalação da armadilha, os insetos coletados eram retirados e na semana seguinte as armadilhas eram reinstaladas durante os períodos de agosto de 1997 a agosto de 1998 em Piracicaba/SP, e de agosto de 1998 a agosto de 1999 em Aquidauana/MS.

Após a triagem e identificação dos besouros, realizou-se a extração dos ácaros presentes nestes. Para a localização dos ácaros, inicialmente os apêndices móveis dos besouros, eram retirados do resto do corpo, e posteriormente destacava-se a cabeça do tórax e o abdome do tórax. Com o inseto fragmentado podia-se facilmente localizar os ácaros. Antes de serem montados, os ácaros foram acondicionados em solução de Vitzthum, e transferidos para estufa a $45^{\circ} \mathrm{C}$ por 48 horas para a clarificação. Em seguida 
foram transferidos para lâminas de montagem em meio de Hoyer's, onde permaneciam por 7 dias em estufa a $45^{\circ} \mathrm{C}$.

Os ácaros foram depositados no Museu de Acarologia da ESALQ/USP em Piracicaba/SP, e na UEMS em Aquidauana/MS. Os besouros coprófagos foram depositados na UEMS em AquidauanaMS.

\subsubsection{Análise faunística}

A análise faunística dos ácaros associados aos besouros coprófagos foi baseada nos índices de diversidade, freqüência, constância e abundância (Silveira Neto et al., 1976) como segue:

Índice de Diversidade. Expressa a relação entre os números de espécies e de indivíduos de uma comunidade. É utilizado para representar a diversidade de espécies de um ecossistema. Esse índice foi calculado pela fórmula em que:

$$
\alpha=\frac{S-1}{\ln N}
$$

$\propto=$ índice de diversidade,

$\mathbf{S}=$ número de táxons coletados,

In = logaritmo neperiano do número de indivíduos coletados,

$\mathbf{N}=$ número total de exemplares coletados na área amostrada.

Freqüência. É a porcentagem do número de indivíduos de uma determinada espécie, em relação ao número total de indivíduos coletadas no ambiente amostrado. $\mathrm{O}$ índice de freqüência foi calculado pela fórmula:

$$
F=\frac{n}{N} \times 100
$$


em que:

$\mathbf{F}=$ freqüência $(\%)$,

$\mathbf{n}=$ número de exemplares da cada espécie coletada,

$\mathbf{N}=$ número total de exemplares das espécies coletadas.

A partir dos resultados obtidos, foi estabelecida uma classe de freqüência para as espécies, de acordo com o intervalo de confiança (IC) da média aritmética a $5 \%$ de probabilidade. Podem ser estabelecidas as seguintes classes:

- pouco frequiente (pf) - quando a porcentagem do número de indivíduos capturados da espécie for menor que o limite inferior do IC a $5 \%$ de probabilidade;

- freqüente (f) - quando a porcentagem do número de indivíduos capturados da espécie situa-se dentro do IC a $5 \%$ de probabilidade;

- muito freqüente $(\mathrm{mf})$ - quando a porcentagem do número de indivíduos da espécie for maior que o limite superior do IC a $5 \%$ de probabilidade.

Constância. Porcentagem de ocorrência das espécies encontradas em um levantamento. A constância foi calcula pela fórmula:

$$
C=\frac{P}{N} x 100
$$

em que:

C = constância,

$\mathbf{P}=$ número de coletas contendo a espécie,

$\mathbf{N}=$ número total de coletas realizadas.

As espécies foram distribuídas em classes, calculadas através do intervalo de confiança (IC) da média aritmética, a $5 \%$ de probabilidade:

- Espécie constante $(w)$ - quando a porcentagem de coletas, contendo a espécie, for maior que o limite superior do IC a $5 \%$ de probabilidade; 
- Espécie acessória (y) - quando a porcentagem de coletas, contendo a espécie, situa-se dentro do IC a $5 \%$ de probabilidade;

- Espécie acidental (z) - quando a porcentagem de coletas, contendo a espécie, for menor que o limite inferior do IC a $5 \%$ de probabilidade.

Abundância. Refere-se ao número de indivíduos de uma determinada categoria taxonômica por unidade de superfície ou volume e varia no espaço e no tempo. Foi calculada empregando-se o desvio padrão e o intervalo de confiança da média aritmética a $1 \%$ e a $5 \%$ de probabilidade.

Para se estimar a abundância das espécies, adotaram-se as seguintes classes:

- raro (r) - quando o número de indivíduos capturados da espécie for menor que o limite inferior do IC a $1 \%$ de probabilidade;

- disperso (d) - quando o número de indivíduos capturados da espécie situa-se entre os limites inferiores do IC a $5 \%$ e a $1 \%$ de probabilidade;

- comum (c) - quando o número de indivíduos capturados da espécie situa-se dentro do IC a $5 \%$ de probabilidade;

- abundante (a) - quando o número de indivíduos capturados da espécie situa-se entre os limites superiores do IC a $5 \%$ e a $1 \%$ de probabilidade;

- muito abundante (ma) - quando o número de indivíduos capturados da espécie for maior que o limite superior do IC a $1 \%$ de probabilidade.

\subsection{Resultados e Discussão}

Foram coletados 4648 espécimes de besouros coprófagos, de um total de 16 espécies. Em Aquidauana/MS foram coletados 1767 espécimes pertencentes a 15 diferentes espécies, e 2881 espécimes em 07 diferentes espécies em Piracicaba/SP (Tabela 3.1).

Das 16 espécies de besouros coletadas, encontrou-se ácaros associados com 11 espécies. Dos besouros coprófagos extraiu-se um total de 1485 espécimes em 11 
diferentes espécies de ácaros da família Macrochelidae, sendo 525 espécimes representadas por 10 espécies em Aquidauana/MS, e 960 espécimes representadas por 09 espécies em Piracicaba/SP (Tabela 3.2).

Dos 525 espécimes de ácaros coletados em Aquidauana/MS, 182 (34,67\%) espécimes estavam associados com Digitonthophagus gazella e 159 (30,28\%) espécimes associados com Dichotomius bos, ou seja $64,95 \%$ dos espécimes coletados estavam associados com apenas duas espécies de besouros coprófagos. Em Piracicaba/SP, dos 960 espécimes coletados 862 estavam associados com Dichotomius bos, ou seja 89,79\% dos espécimes estavam associados com essa espécie de besouro coprófago (Tabela 3.2).

Algumas espécies de besouros coprófagos são hospedeiros de várias espécies de ácaros. Dichotomius bos, por exemplo, é hospedeiro de 09 espécies de ácaros, o que é definido por Krantz (1967), como múltipla forese, entretanto, com Ontherus sulcator e Ataenius picinus foi encontrado associado apenas Macrocheles merdarius (Tabela 3.2).

Segundo Flechtmann et al. (1995a) os besouros podem ser divididos em: tamanho pequeno (até $5,25 \mathrm{~mm})$, médio $(5,26$ a $10 \mathrm{~mm}$ ) e grande (acima de $10 \mathrm{~mm}$ ). Besouros de tamanho grande como Dichotomius bos, D. nisus e Digitonthophagus gazella, foram encontrados em algumas ocasiões, sem qualquer ácaro em seu corpo, entretanto, em algumas coletas grande quantidade de ácaros foram encontrados, principalmente associados com $D$. bos e $D$. gazella.

O maior número de ácaros (60 ácaros) da família Macrochelidae encontrados em D. bos, estavam localizados na região gular, base dos olhos e antenas, nos tarsos e tíbias do segundo e terceiro pares de pernas e na membrana intersegmental entre o prótorax e pterotórax, em Piracicaba/SP. Desses, 41 eram M. subbadius, 06 M. merdarius, 06 M. mammifer, 03 Macrocheles spl e 04 Glyptholaspis confusa.

Em Digitonthophagus gazella, o maior número de ácaros (50 ácaros) da família Macrochelidae foi encontrado em Aquidauana/MS, sendo que todos os ácaros estavam localizados na região gular do besouro. Desses, 28 eram M. merdarius, 08 M. insignitus, 06 Macrocheles spl e 08 Macrocheles sp2.. Em várias coletas realizadas, encontrou-se espécimes deste besouro sem qualquer ácaro presente. 
Nos besouros de tamanho médio, como Onthophagus hirculus, o maior número de ácaros encontrados foi 13. Foram encontrados 03 espécimes de Macrocheles mammifer, 09 espécimes de Macrocheles sp2 e 01 espécime de Macrocheles spl, na região gular e nos tarsos do terceiro par de pernas do besouro.

Em besouros de pequeno tamanho, como Aphodius lividus, o maior número de ácaros encontrados foi $05 \mathrm{M}$. merdarius, que estavam localizados sob os élitros do besouro, em Piracicaba/SP. Em várias coletas nenhum ácaro foi encontrado em $A$. lividus, tanto em Piracicaba/SP, como em Aquidauana/MS.

A maior diversidade de ácaros foi observada em Aquidauana/MS (Tabela 3.3), onde também encontrou-se o maior número de besouros hospedeiros.

Vários ácaros foram encontrados associados com os besouros coprófagos:

\section{Glyptholaspis confusa (Foa)}

Glyptholaspis confusa foi encontrado nas duas localidades estudadas, ocorrendo entretanto em maior quantidade em Piracicaba/SP, associado com Dichotomius bos e Aphodius lividus, enquanto que em Aquidauana/MS, foi encontrada apenas em Digitonthophagus gazella (Tabela 3.2).

Halffter \& Matthews (1971), realizaram uma revisão de literatura onde relacionaram vários organismos associados aos besouros coprófagos, e dentre eles $G$. confusa associada com uma espécie de besouro coprófago.

Através da análise faunística, esta espécie foi considerada como pouco freqüente, acidental e rara em Aquidauana/MS, e freqüente, acessória e constante em Piracicaba/SP (Tabela 3.3).

Glyptholaspis confusa foi extraído d os tarsos e tíbias do segundo e terceiro par de pernas dos besouros coprófagos, em todas as ocasiões. O maior número encontrado foi 06 ácaros nos tarsos de um espécime de Dichotomius bos em Piracicaba/SP.

Como esse ácaro possui tamanho relativamente grande (cerca de $1238 \mu \mathrm{m}$ de comprimento do escudo dorsal, segundo Halliday \& Holm (1987)), os tarsos das pernas dos besouros parecem ser o local mais apropriado para se fixarem, pois se estivessem em outro local, poderiam ser retirados. O tamanho desse ácaro, parece não permitir que se 
posicione sob os élitros dos besouros pequenos, principalmente dos gêneros Aphodius, Ataenius e Trichillum.

No presente experimento, Glyptholaspis confusa foi coletado de besouros coprófagos que ocorrem em áreas de pastagem utilizando assim fezes de bovinos para alimentação. Entretanto, esse tipo de fezes não são apenas os únicos excrementos onde esse ácaro pode estar presente, pois Axtell (1963), observou esse ácaro em fezes de diferentes animais doméstico (bovinos, ovelhas, frangos e patos), enquanto que Mattos (1992), encontrou vários espécimes em fezes de galinhas poedeiras.

Nas fezes de bovinos esse ácaro é importante predador de estágios imaturos de mosca doméstica (Axtell, 1961), predando uma média de 9,9 indivíduos imaturos por dia. Halliday \& Holm (1987) verificaram que esse ácaro é um importante predador de ovos de moscas pragas de bovinos, e que os ácaros de maior tamanho, como Glyptholaspis confusa, geralmente são predadores mais eficientes do que espécies de ácaros de menor tamanho.

\section{Macrocheles merdarius (Berlese)}

Esta espécie foi coletada em grande quantidade nas duas localidades estudadas. Em Aquidauana/MS, os besouros coprófagos hospedeiros de Macrocheles merdarius foram: Dichotomius bos, Ontherus sulcator, Ontherus appendiculatus, Digitonthophagus gazella, Ateuchus sp., Aphodius lividus e Ataenius sp.. Em Piracicaba/SP, as espécies de besouros coprófagos com as quais estava associada foram: Dichotomius bos, Aphodius lividus e Ataenius picinus (Tabela 3.2).

Wallace (1986) relacionou vários besouros coprófagos hospedeiros para esse ácaro, e considerou-o como cosmopolita, pois, ocorre em todos os Estados da Austrália. Halffter \& Matthews (1971) ao realizarem uma revisão de literatura, relacionaram várias espécies de besouros coprófagos hospedeiros de M. merdarius.

Axtell (1963) encontrou essa espécie em diferentes fezes de animais domésticos (bovinos, eqüinos, ovelhas, frangos e patos), enquanto que Mattos (1992), encontrou em fezes de galinhas poedeiras e Krantz \& Whitaker Jr. (1988) em um pequeno mamífero (Rattus norvegicus). 
Halliday \& Holm (1987) verificaram que esse ácaro por apresentar pequeno tamanho (480 $\mu \mathrm{m}$ de comprimento do escudo dorsal), preda pequeno número de ovos e larvas de moscas pragas de bovinos.

Várias são as regiões do corpo dos besouros coprófagos onde esse ácaro pode ser encontrado, como nos palpos labiais, nos pêlos das várias regiões das pernas, sob os élitros, na base das antenas e na região gular.

Os maiores números desse ácaro presente em um besouro hospedeiro foram 05 , localizados sob os élitros de Aphodius lividus e 10 na região gular de $D$. bos em Piracicaba/SP. Em Aquidauana/MS, 28 espécimes de M. merdarius estavam associados com Digitonthophagus gazella, sendo que todos ácaros estavam localizados na região gular.

A coleta de M. merdarius em Aquidauana/MS, foi realizado nos meses de janeiro a setembro, enquanto que em Piracicaba/SP, foi nos meses de janeiro, fevereiro, março, abril, agosto e novembro. Os meses de ocorrência do ácaro demonstram que tanto no período mais quente e úmido (outubro a abril), e frio e seco (maio a setembro) do ano, ocorreu em campo nas duas localidades estudadas.

Estudando a sazonalidade de ácaros associados aos besouros coprófagos, Wallace \& Holm (1985), verificaram que M. merdarius ocorreu em maior quantidade durante os meses de janeiro a maio, que são os meses mais quentes do ano, na Austrália.

Realizando-se a análise faunística, esta espécie foi considerada muito freqüente, constante e muito abundante em Aquidauana/MS, e freqüente, constante e comum em Piracicaba/SP (Tabela 3.3).

Os ácaros dessa espécie utilizam os besouros coprófagos apenas como agentes de dispersão. Pode-se entender que os besouros são excelentes dispersores desse ácaro, pois as áreas experimentais estudadas estão distantes cerca de $1.000 \mathrm{~km}$, e essa espécie foi coletada em ambas. Se apresentassem apenas deslocamento próprio (caminhamento), provavelmente esta espécie teria taxa de dispersão bastante restrita, mas ao se fixar nos besouros ou em outros agentes, sem dúvida conseguem em muito se dispersarem. 


\section{Macrocheles mammifer Berlese}

Em Aquidauana/MS, Macrocheles mammifer estava associada aos besouros coprófagos: Dichotomius bos, Onthophagus hirculus e Digitonthophagus gazella e em Piracicaba/SP, em D. bos e Aphodius lividus (Tabela 3.2).

Wallace (1986) em seus estudos, encontrou na Austrália uma espécie de besouro coprófago hospedeiro de M. mammifer. Essa espécie pode auxiliar no controle de Haematobia irritans exigua (praga de bovinos), devido a mortalidade que pode causar nos estágios imaturos dessa mosca (Halliday \& Holm, 1987).

Várias são as regiões do corpo dos besouros coprófagos onde esse ácaro pode se fixar, como nos palpos labiais, nos pêlos das várias regiões das pernas, na base das antenas e na região gular dos besouros hospedeiros.

Através da análise faunística essa espécie foi considerada pouco freqüente, acidental e dispersa em Aquidauana/MS, e freqüente, acessória e comum em Piracicaba/SP (Tabela 3.3).

Em Aquidauana/MS, foi coletado nos meses de janeiro, fevereiro, abril e agosto e em Piracicaba/SP, nos meses de fevereiro, março, setembro, novembro e dezembro.

Macrocheles mammifer além dos besouros coprófagos, pode também estar associados com alguns pequenos mamíferos (Krantz \& Whitaker Jr., 1988).

\section{Macrocheles subbadius (Berlese)}

Esta espécie foi encontrada nas duas localidades estudadas, ocorrendo entretanto, em maior quantidade em Piracicaba/SP. Nesta localidade apareceu associada apenas com Dichotomius bos, sendo que dos 960 espécimes de ácaros da família Macrochelidae coletados nesta localidade, 536 (55,83\%) eram M. subbadius, enquanto que em Aquidauana/MS, estava associada com D. bos, Dichotomius nisus e Canthidium megathopoides, mas, dos 90 espécimes de M. subbadius coletados, 88 estavam associados com D. bos (Tabela 3.2).

Wallace (1986) estudou as espécies de ácaros associados aos besouros na Austrália, mas não encontrou nenhum besouro hospedeiro de $M$. subbadius. 
As quantidades de M. subbadius associados com D. bos, demonstram que a grande maioria dos ácaros coletados parecem apresentar preferência por esse besouro, como espécie hospedeira.

Krantz \& Mellott (1972) realizaram estudos em laboratório onde verificaram a especificidade hospedeira de duas espécies de Macrochelidae (Macrocheles mycotrupetes e $M$. peltotrupetes), e encontraram que os ácaros apresentaram nítida preferência por se fixarem em espécies de besouros da subfamília Geotrupinae, podendo entretanto, utilizarem outros besouros como hospedeiros. Verificaram ainda que a especificidade hospedeira não é apenas baseada em especialização de nicho e preferência pelo besouro hospedeiro.

Krantz (1991) verificou que alguns Macrochelidae podem localizar o besouro hospedeiro devido a liberação de cairomônios. Krantz \& Royce (1994) estudaram a biologia e comportamento de Macrocheles mycotrupetes verificando que o ácaro pode localizar o besouro hospedeiro (Geotrupes egeriei) através de cairomônios liberados por este.

Os meses de ocorrência desse ácaro foram, os meses de janeiro, fevereiro, março e abril em Piracicaba/SP e os meses de janeiro, fevereiro, março, novembro e dezembro em Aquidauana/MS. Esse ácaro ocorreu apenas nos períodos mais quentes e úmidos do ano, nas duas localidades estudadas, sendo também o período de ocorrência de $D$. bos no campo.

O comportamento do ácaro de ocorrer no período em que o besouro está ativo no campo, pode ser entendido como uma evolução da espécie, pois este pode estar adaptando seu ciclo biológico ao do besouro hospedeiro, o que contribui para reforçar a idéia de preferência com o besouro hospedeiro. Nesse contexto, M. subbadius pode estar apresentando preferência por se fixar em $D$. bos, podendo entretanto, utilizar outros besouros hospedeiros mas em menor freqüência. Como verificado para outras espécies de Macrocheles é provável que o ácaro localize o besouro através de cairomônio que venha a liberar. Desta forma pode-se explicar parcialmente a grande quantidade de ácaro, encontrado no besouro hospedeiro. 
Através da análise faunística verificou-se que $M$. subbadius é muito freqüente, acessória e abundante em Aquidauana/MS, e muito freqüente, acessória e muito abundante em Piracicaba/SP (Tabela 3.3).

No corpo dos besouros coprófagos, o ácaro foi encontrado na base das antenas, nos pêlos das várias regiões das pernas dos besouros, na região gular e na membrana intersegmental entre o protórax e pterotórax. O maior número de $M$. subbadius encontrado em $D$. bos, foi 41 ácaros, sendo que 26 estavam localizados na região gular e 15 na membrana intersegmental entre protórax e pterotórax, em Piracicaba/SP.

Axtell (1961) encontrou M. subbadius em fezes de bovinos e eqüinos e verificou que predava estágios imaturos de mosca doméstica, já Axtell (1963) encontrou o ácaro em várias fezes de animais domésticos (bovino, eqüinos e ovelhas).

Esse ácaro não aparece associado apenas com besouros coprófagos, mas também em pequeno mamífero (Krantz \& Whitaker Jr., 1988).

No presente estudo esse ácaro apresenta associação apenas forética com os besouros coprófagos, utilizando-os apenas como agentes de dispersão. Entretanto, com uma espécie de díptero (Drosophila nigrospiracula), Polak (1996), estudou a relação existente entre ambos, e verificou que o ácaro se fixa no abdome do díptero e se alimenta da hemolinfa que extravasa do local onde as quelíceras se fixam. $O$ ácaro nesse caso é tido como ectoparasito do díptero, pois se alimenta da hemolinfa do hospedeiro.

\section{Macrocheles insignitus Berlese}

O maior número de besouros hospedeiros para $M$. insignitus, foi encontrado em Aquidauana/MS, onde coletou-se de: Dichotomius bos, D. nisus, Ontherus appendiculatus, Digitonthophagus gazella, Canthidium megathopoides, Ateuchus sp. e Ataenius sp.. Em Piracicaba/SP, o ácaro foi coletado em D. bos e Aphodius lividus (Tabela 3.2).

Através da análise faunística foi considerada como freqüente, constante e comum em Aquidauana/MS, e freqüente, acidental e comum em Piracicaba/SP (Tabela 3.3).

Em Aquidauana/MS, M. insignitus foi coletada nos meses de janeiro, fevereiro, março, abril, maio, junho e agosto e em Piracicaba/SP, nos meses de janeiro e fevereiro. 
Esse ácaro foi encontrado ainda associado com um pequeno mamífero por Krantz \& Whitaker Jr. (1988).

\section{Macrocheles roquensis Mendes \& Lizaso}

Essa espécie ocorreu nas duas localidades estudadas, entretanto, em maior número em Aquidauana/MS. O besouro ao qual foi encontrada associada em Piracicaba/SP, foi $D$. bos, enquanto que em Aquidauana/MS, nas espécies $D$. bos, Ontherus appendiculatus, Onthophagus hirculus, Digitonthophagus gazella e Ataenius sp. (Tabela 3.2).

Em Piracicaba/SP, ocorreu nos meses de janeiro, fevereiro, março, abril e dezembro, enquanto que em Aquidauana/MS, ocorreu nos meses de janeiro, fevereiro, março, abril, maio, agosto e novembro. Nos besouros coprófagos foi encontrado fixado na região gular, na base das antenas e olhos compostos.

Pela análise faunística essa espécie foi considerada como muito freqüente, constante e abundante em Aquidauana/MS, e freqüente, acessória e comum em Piracicaba/SP (Tabela 3.3).

Macrocheles roquensis foi coletado em várias localidades do estado de São Paulo como, São Roque, São Paulo, Nova Odessa, Pindamonhangaba e Ribeirão Preto, em fezes bovinas (Mendes \& Lizaso, 1992).

\section{Macrocheles robustulus (Berlese)}

Encontrou-se $M$. robustulus associado com os besouros Dichotomius bos e Aphodius lividus em Piracicaba/SP, e Dichotomius bos e Onthophagus hirculus em Aquidauana/MS (Tabela 3.2).

Wallace (1986) estudou as espécies de ácaros associados aos besouros coprófagos na Austrália e encontrou M. robustulus associado com alguns deles.

Em Aquidauana MS, os meses de ocorrência de M. robustulus foram em janeiro e agosto. Em Piracicaba/SP, ocorreu nos meses de janeiro, fevereiro, março e novembro. 
Nos besouros coprófagos foram encontrados fixados na região gular, na base das antenas, base dos olhos compostos e sob os élitros.

Pela análise faunística foi considerado pouco freqüente, acidental e rara em Aquidauana/MS, e freqüente, acessória e comum em Piracicaba/SP (Tabela 3.3).

Axtell (1961 e 1963) verificou que M. robustulus pode predar cerca de 4,6 imaturos de mosca doméstica por dia e também ser encontrado em fezes de alguns animais domésticos (bovinos, eqüinos, ovelhas e patos). Macrocheles robustulus pode auxiliar ainda no controle de estágios imaturos de moscas pragas de bovinos na Austrália, segundo Halliday \& Holm (1987).

Costa (1966) realizou a criação de $M$. robustulus em salas com temperatura ambiente, e verificou que o seu período embrionário pode durar de 1 a 6 dias, de larva a fềmea adulta cerca de 14 dias, enquanto que de larva a macho adulto de 9 a 11 dias.

\section{Macrocheles sp1}

Essa espécie foi coletada em maior número em Aquidauana/MS, e estava associada com Dichotomius bos, D. nisus, Ontherus appendiculatus, Digitonthophagus gazella e Canthidium megathopoides, enquanto que em Piracicaba/SP, estava associado apenas com D. bos (Tabela 3.2).

Em Piracicaba/SP, ocorreu apenas nos meses de fevereiro, março e abril, enquanto que em Aquidauana/MS, ocorreu nos meses de janeiro, fevereiro, março, abril, maio, agosto, outubro e novembro.

Através da análise faunística foi considerado como muito freqüente, constante e abundante em Aquidauana/MS, e freqüente, acessória e comum em Piracicaba/SP.

Nos besouros coprófagos foi encontrado fixado na região gular, na base das antenas, olhos compostos e na membrana intersegmental entre o protórax e pterotórax.

\section{Macrocheles sp2}

Essa espécie foi coletada apenas em Piracicaba/SP e encontrada associada com D. bos (Tabela 3.2), nos meses de fevereiro, março e abril. 
Através da análise faunística foi considerada como freqüente, acessória e comum (Tabela 3.3). Estava fixada na base das antenas, na região gular e na base dos olhos compostos dos besouros.

Da mesma forma como observado em Macrocheles subbadius, Macrocheles sp2, parece demonstrar certa preferência hospedeira por D. bos, pois foi encontrado associado apenas com essa espécie de besouro. Porém, por ter sido encontrado apenas em uma localidade e o número de espécimes coletados não ser muito expressivo, haveria a necessidade de se realizar novas coletas, para que se possa confirmar ou não a preferência hospedeira desse ácaro por D. bos.

Wallace (1986) estudou as espécies de Macrochelidae associados com besouros coprófagos na Austrália, onde encontrou 21 espécies das quais foram identificadas apenas (Macrocheles) a nível genérico. Foram encontradas 13 espécies associadas com besouros coprófagos nativos e 08 em fezes de bovinos ou coletadas em armadilhas "pitfall".

\section{Macrocheles sp3}

Esse ácaro foi coletado apenas em Aquidauana/MS e estava associado apenas com D. bos, Ontherus appendiculatus e Canthidium megathopoides (Tabela 3.2).

Dos 67 espécimes coletados, 64 estavam associados com O. appendiculatus. Da mesma forma como observado e discutido para Macrocheles sp2, pode-se verificar uma certa preferência de Macrocheles sp3, com O. appendiculatus. Há, entretanto, necessidade de se realizar mais coletas, inclusive em outras localidades, para que se tenha informações mais precisas, sobre a existência ou não de preferência hospedeira.

Esse ácaro ocorreu nos meses de janeiro, fevereiro, março e outubro, que são os meses mais quentes e úmidos do ano (outubro a abril). Foram localizados nos besouros hospedeiros na região gular, na base das antenas e base dos olhos compostos.

Através da análise faunística essa espécie foi considerada como freqüente, acessória e comum em Aquidauana/MS (Tabela 3.3). 


\section{Macrocheles sp4}

Esse ácaro foi coletado apenas em Aquidauana/MS e encontrado associado com Digitonthophagus gazella e Ataenius sp. (Tabela 3.2).

Foi coletado apenas no mês de fevereiro e estava localizado na região gular dos besouros hospedeiros. Através da análise faunística foi considerado como pouco freqüente, acidental e rara em Aquidauana/MS (Tabela 3.3).

Esse ácaro como todos os demais coletados da família Macrochelidae, utilizam os besouros apenas como agentes de dispersão, não ocasionando nenhum dano aos mesmos.

Para o presente trabalho é possivel concluir que; 1) os besouros coprófagos são importantes agentes de dispersão para os ácaros, principalmente para as fêmeas, que foram as encontradas associadas aos besouros; 2) besouros de pequeno tamanho podem ser hospedeiros de várias espécies de ácaros, da mesma forma como os de maior tamanho; 3) Glyptholaspis confusa utiliza principalmente os tarsos do segundo e terceiro par de pernas dos besouros para se fixar durante o período de dispersão; 4) Macrocheles subbadius utiliza Dichotomius bos como principal besouro hospedeiro. 
Tabela 3.1. Relação das espécies e quantidades de besouros coprófagos coletados em área de pastagem em Aquidauana/MS (de agosto de 1998 a agosto de 1999) e Piracicaba/SP (de agosto de 1997 a agosto de 1998).

\begin{tabular}{|c|c|c|}
\hline Espécies & Aquidauana & Piracicaba \\
\hline Aphodius lividus (Olivier) & 136 & 2745 \\
\hline Aphodius nigrita (Olivier) & 02 & $=$ \\
\hline Ataenius picinus (Harold) & - & 07 \\
\hline Ataenius sculptor (Harold) & 55 & - \\
\hline Ataenius sp. Harold & 1167 & 29 \\
\hline Ateuchus sp. Harold & 05 & $=$ \\
\hline Onthophagus hirculus Mannerheim & 15 & 01 \\
\hline Digitonthophagus gazella (Fabricius) & 255 & - \\
\hline Trichillum externepunctatum Borre & 18 & 09 \\
\hline Dichotomius bos (Blanchard) & 55 & 89 \\
\hline Dichotomius nisus (Olivier) & 05 & 01 \\
\hline Dichotomius sp. Hope & 01 & - \\
\hline Canthidium megathopoides Boucomont & 04 & - \\
\hline Diabroctis mimas (Linné) & 01 & - \\
\hline Ontherus sulcator (Fabricius) & 07 & - \\
\hline Ontherus appendiculatus (Mannerheim) & 41 & - \\
\hline Total & 1767 & 2881 \\
\hline Total Geral & \multicolumn{2}{|c|}{4648} \\
\hline
\end{tabular}


Tabela 3.2. Relação das espécies e quantidades de ácaros associados com besouros coprófagos, coletados em área de pastagem em Aquidauana/MS (de agosto de 1998 a agosto de 1999), e Piracicaba/SP (de agosto de 1997 a agosto de 1998).

\begin{tabular}{|c|c|c|c|c|c|c|c|c|c|c|c|c|}
\hline Localidade/Espécie & 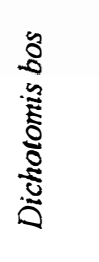 & 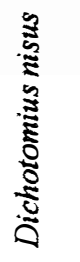 & 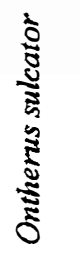 & 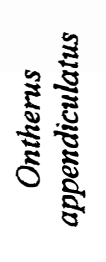 & 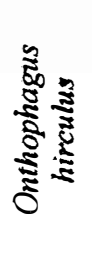 & 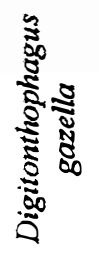 & 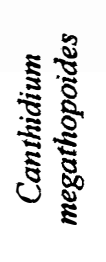 & 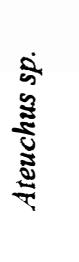 & 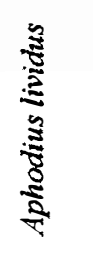 & 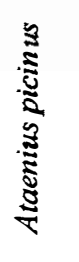 & 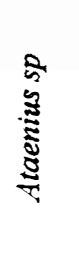 & 즁 \\
\hline \multicolumn{13}{|l|}{ Aquidauana } \\
\hline $\begin{array}{l}\text { Glyptholaspis confusa } \\
\text { (Foa) }\end{array}$ & - & - & - & - & - & 02 & - & - & - & $=$ & - & 02 \\
\hline $\begin{array}{l}\text { Macrocheles merdarius } \\
\text { (Berlese) }\end{array}$ & 01 & - & 01 & 02 & $=$ & 88 & - & 01 & 13 & - & 11 & 117 \\
\hline $\begin{array}{l}\text { Macrocheles mammifer } \\
\text { Berlese }\end{array}$ & 01 & - & - & - & 05 & 05 & - & - & $=$ & - & - & 11 \\
\hline $\begin{array}{l}\text { Macrocheles subbadius } \\
\text { (Berlese) }\end{array}$ & 88 & 01 & $=$ & - & - & - & 01 & - & - & - & - & 90 \\
\hline $\begin{array}{l}\text { Macrocheles insignitus } \\
\text { Berlese }\end{array}$ & 02 & 07 & - & 05 & - & 20 & 05 & 02 & - & - & 12 & 53 \\
\hline Macrocheles roquensis & & & & & & & & & & & & \\
\hline $\begin{array}{l}\text { Mendes \& Lizaso } \\
\text { Macrocheles robustulus }\end{array}$ & 30 & - & - & 1 & 15 & 44 & - & - & - & - & 2 & 92 \\
\hline (Berlese) & 1 & - & - & - & 3 & - & - & - & - & - & - & 04 \\
\hline Macrocheles spl & 34 & 14 & - & 15 & - & 22 & 1 & - & - & - & - & 86 \\
\hline Macrocheles sp3 & 2 & - & & 64 & - & - & 1 & - & - & - & - & 67 \\
\hline Macrocheles sp4 & - & - & - & - & - & 1 & - & - & - & - & 2 & 03 \\
\hline Total & 159 & 22 & 01 & 87 & 23 & 182 & 08 & 03 & 13 & - & 27 & 525 \\
\hline \multicolumn{13}{|l|}{ Piracicaba } \\
\hline $\begin{array}{l}\text { Glyptholaspis confusa } \\
\text { (Foa) }\end{array}$ & 49 & - & - & - & - & - & - & - & 02 & - & - & 51 \\
\hline $\begin{array}{l}\text { Macrocheles merdarius } \\
\text { (Berlese) }\end{array}$ & 58 & - & - & - & - & $=$ & - & - & 53 & 01 & - & 112 \\
\hline $\begin{array}{l}\text { Macrocheles mammifer } \\
\text { Berlese }\end{array}$ & 07 & - & - & - & - & - & $=$ & - & 22 & - & - & 29 \\
\hline $\begin{array}{l}\text { Macrocheles subbadius } \\
\text { (Berlese) }\end{array}$ & 536 & - & - & - & $=$ & - & - & - & $=$ & - & - & 536 \\
\hline $\begin{array}{l}\text { Macrocheles insignitus } \\
\text { Berlese }\end{array}$ & 32 & - & - & - & - & - & $=$ & - & 02 & - & - & 34 \\
\hline Macrocheles roquensis & & & & & & & & & & & & \\
\hline $\begin{array}{l}\text { Mendes \& Lizaso } \\
\text { Macrocheles robustulus }\end{array}$ & 41 & - & - & - & - & - & $=$ & - & - & - & - & 41 \\
\hline (Berlese) & 23 & - & - & - & - & - & - & - & 18 & - & - & 41 \\
\hline Macrocheles spl & 49 & - & - & - & - & - & - & - & - & - & - & 49 \\
\hline Macrocheles sp2 & 67 & - & - & - & - & - & - & - & - & - & - & 67 \\
\hline Total & 862 & - & - & - & - & - & - & - & 97 & 01 & - & 960 \\
\hline Total Geral & 1021 & 22 & 01 & 87 & 23 & 182 & 08 & 03 & 110 & 01 & 27 & 1485 \\
\hline
\end{tabular}


Tabela 3.3. Distribuição de freqüência (F), constância (C), abundância (A) e diversidade para as espécies de ácaros extraídos de besouros coprófagos, coletados em áreas de pastagem em Aquidauana/MS (de agosto de 1998 a agosto de 1999), e Piracicaba/SP (de agosto de 1997 a agosto de 1998).

\begin{tabular}{|c|c|c|c|c|c|c|}
\hline \multirow[t]{2}{*}{ Espécies } & \multicolumn{3}{|c|}{ Aquidauana } & \multicolumn{3}{|c|}{ Piracicaba } \\
\hline & $F^{(1)}$ & $C^{(2)}$ & $A^{(3)}$ & $F^{(1)}$ & $C^{(2)}$ & $\mathbf{A}^{(\mathbf{3})}$ \\
\hline $\begin{array}{l}\text { Glyptholaspis confusa } \\
\text { (Foa) }\end{array}$ & $0,38(\mathrm{PF})$ & $1,89(\mathrm{Z})$ & $R$ & $5,32(\mathrm{~F})$ & $16(\mathrm{Y})$ & $\mathrm{C}$ \\
\hline $\begin{array}{l}\text { Macrocheles merdarius } \\
\text { (Berlese) }\end{array}$ & 22,37 (MF) & $32,08(W)$ & MA & $11,67(\mathrm{~F})$ & $26(W)$ & $\mathrm{C}$ \\
\hline $\begin{array}{l}\text { Macrocheles mammifer } \\
\text { Berlese }\end{array}$ & $2,10(\mathrm{PF})$ & $7,55(\mathrm{Z})$ & D & $3,02(F)$ & $18(\mathrm{Y})$ & c \\
\hline $\begin{array}{l}\text { Macrocheles subbadius } \\
\text { (Berlese) }\end{array}$ & 17,21 (MF) & $15,09(\mathrm{Y})$ & A & $55,83(\mathrm{MF})$ & $20(Y)$ & MA \\
\hline $\begin{array}{l}\text { Macrocheles insignitus } \\
\text { Berlese } \\
\text { Macrocheles roquensis }\end{array}$ & $10,13(\mathrm{~F})$ & $26,42(W)$ & $\mathrm{C}$ & $3,54(\mathrm{~F})$ & $04(\mathrm{Z})$ & C \\
\hline Mendes \& Lizaso & 17,59 (MF) & $28,30(W)$ & A & $4,27(F)$ & $14(Y)$ & C \\
\hline $\begin{array}{l}\text { Macrocheles robustulus } \\
\text { (Berlese) }\end{array}$ & 0,77 (PF) & $3,77(Z)$ & $\mathrm{R}$ & $4,27(\mathrm{~F})$ & $18(Y)$ & $\mathrm{C}$ \\
\hline Macrocheles spl & 16,44 (MF) & $26,42(\mathrm{~W})$ & A & $5,10(\mathrm{~F})$ & $14(\mathrm{Y})$ & C \\
\hline Macrocheles sp2 & - & - & - & $6,98(F)$ & $14(\mathrm{Y})$ & C \\
\hline Macrocheles sp3 & $12,43(\mathrm{~F})$ & $15,09(\mathrm{Y})$ & $\mathrm{C}$ & - & - & - \\
\hline Macrocheles sp4 & $0,58(\mathrm{PF})$ & $3,77(\mathrm{Z})$ & $\mathrm{R}$ & - & - & - \\
\hline Diversidade & & 1,44 & & & 1,17 & \\
\hline
\end{tabular}

(i) $\mathrm{PF}=$ pouco freqüente; $\mathrm{F}=$ freqüente; $\mathrm{MF} ;$ muito freqüente

(2) $\mathrm{Z}=$ acidental; $\mathrm{Y}=$ acessória; $\mathrm{W}=$ constante

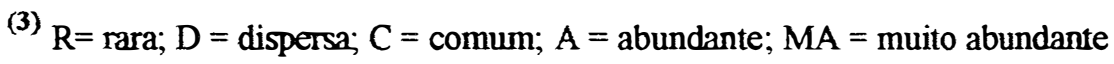




\section{4 ÁCAROS (ACARI) ASSOCIADOS AOS BESOUROS COPRÓFAGOS (COLEOPTERA: SCARABAEIDAE). FAMÍLIAS SCUTACARIDAE E PYGMEPHORIDAE (HETEROSTIGMATA).}

\subsection{Introdução}

São escassas as informações sobre a ocorrência de ácaros das famílias Scutacaridae e Pygmephoridae, no Brasil. Os ácaros da família Scutacaridae ocorrem em fezes de animais e aves (Mahunka \& Rohde Jr., 1970; Ebermann \& Palacios-Vargas, 1988); podem estar associados com insetos (Delfinado \& Baker, 1976; Binns, 1979; Metwali, 1984; Ebermann, 1988); associados com plantas medicinais e aromáticas (Momen \& El-Bagoury, 1989), ou ainda, serem encontrados diretamente no solo (Ebermann, 1986a; Momen \& Curry, 1987). Com relação a taxonomia dessa família, vários são as espécies descritas e estudadas (Mahunka e Rohde Jr., 1970; Momen \& Curry, 1988; Ebermann, 1986b, 1997bc).

Na família Pygmephoridae os ácaros podem ser pragas de cogumelos cultivados (Kaliszewski \& Rack, 1986), ou aparecer associado com artrópodos e mamíferos (Smiley, 1978; Stephen \& Kinn, 1980; Whitaker Jr. et al., 1982; Smiley \& Whitaker Jr., 1984; Cudmore et al., 1987). Várias são as espécies descritas e estudadas, nessa família (Moser \& Cross, 1975; Lindquist, 1985; Kaliszewski, 1988a; Dastych \& Rack, 1993a; Gao et al., 1997).

O presente trabalho teve por objetivo conhecer as espécies de ácaros das famílias Scutacaridae e Pygmephoridae, que ocorrem associados aos besouros coprófagos da família Scarabaeidae. 


\subsection{Material e Métodos}

\subsubsection{Coleta de besouros coprófagos e extração de ácaros}

Para realizar a coleta de besouros coprófagos foram utilizadas 4 armadilhas "pitfall" iscadas com massa fecal fresca de bovinos, instaladas em áreas de pastagem na Universidade de São Paulo (ESALQ/USP) em Piracicaba/SP e, na Universidade Estadual de Mato Grosso do Sul (UEMS), no município de Aquidauana/MS. Através do uso de armadilha luminosa, instalada ao lado de área de pastagem na Fazenda Experimental da Empresa Brasileira de Pesquisa Agropecuária - Centro de Pesquisa Agropecuária de Clima Temperado (EMBRAPA-CPACT), realizou-se a coleta de besouros em Capão do Leão/RS.

O uso de armadilhas "pitfall" tem sido empregada em estudos onde avalia-se a distribuição e comportamento populacional de besouros coprófagos (Lobo et al., 1988). A armadilha "pitfall" consiste de um tripé de metal com cerca de $28 \mathrm{~cm}$ de altura, ao qual dependura-se um volume de cerca de $700 \mathrm{ml}$ de massa fecal fresca de bovino, envolta em tecido de voal. Imediatamente sob a massa, são colocados dois copos plásticos, um encaixado dentro do outro, de $350 \mathrm{ml}$ de volume, enterrados ao nível do solo, e preenchido com água e detergente.

Após 24 horas da instalação da armadilha "pitfall", os insetos coletados eram

retirados e na semana seguinte as armadilhas eram reinstaladas. Foram instaladas no período de agosto de 1997 a agosto de 1998 em Piracicaba/SP, e de agosto de 1998 a agosto de 1999 em Aquidauana/MS.

A armadilha luminosa permanecia durante a noite instalada, e na manhã do dia seguinte realizava-se a coleta dos besouros, acondicionando-os em frascos com álcool devidamente identificados. Com essa armadilha foram realizadas 48 coletas de besouros coprófagos, durante o período de dezembro de 1997 a fevereiro de 1998.

A armadilha luminosa é um dos métodos tradicionais mais utilizados no levantamento populacional de insetos (Gallo et al., 1988), e pode também ser utilizado para coleta de besouros coprófagos (Flechtmann et al., 1995c). 
Após a triagem e identificação dos besouros, foram destacados os apêndices móveis dos besouros e posteriormente a cabeça do tórax e o tórax do abdome para retirada dos ácaros presentes. Com o inseto fragmentado podia-se facilmente localizar os ácaros. Em seguida transferia-se os ácaros para lâminas de montagem em meio de Hoyer's, anctando-se ainda o local onde estavam fixados no besouro. Após a montagem em lâminas, os ácaros ficavam por 7 dias em estufa a $45^{\circ} \mathrm{C}$ para secagem da lâmina.

Os ácaros foram depositados no Museu de Zoologia da Universidade de São Paulo em Piracicaba/SP (ESALQ/USP), na Universidade Estadual de Mato Grosso do Sul em Aquidauana (UEMS) e no Museu da Universitaetsplatz (Graz, Austria).

\subsection{Resultados e Discussão}

\subsubsection{Família Scutacaridae}

\section{Pygmodispus (Pygmodispus) bicornutus Ebermann, Rodrigues \& Marchini}

Os espécimes de Pygmodispus (P.) bicornutus coletados, segundo Ebermann et al. $^{3}$, compõe uma espécie nova e, ocorre também nas Ilhas Galapagos.

Em Piracicaba/SP, 49 espécimes de $P$. bicornutus, foram encontrados associados com Aphodius lividus, enquanto no município de Aquidauana/MS, 13 espécimes estavam associados com Digitonthophagus gazella e Ataenius sp1, e em Capão do Leão/RS, 32 espécimes associados com Ataenius sp1, Ataenius sp2 e Aphodius lividus (Tabela 4.1).

Esse ácaro não apresenta especificidade hospedeira, podendo se associar com várias espécies de besouros coprófagos. Os ácaros utilizam várias regiões do corpo dos besouros para se fixarem, como nos pêlos localizados na base e entre as coxas do primeiro par de pernas, nos palpos labiais, na base das antenas e nas várias regiões do tórax e abdome.

\footnotetext{
${ }^{3}$ Ebermann, E.; Rodrigues, S.R.; Marchini, L.C. Pygmodispus (Pygmodispus) bicornutus n.sp., a new phoretic mites species from South America (Acari, Heterostigmata, Scutacaridae). Studies on Neotropical Fauna and Environment.(no prelo).
} 
Os besouros onde os ácaros são encontrados, utilizam fezes de bovinos para se alimentarem e desenvolverem. Alguns ácaros da família Scutacaridae, já foram encontrados em fezes de animais, como por exemplo Heterodispus verrucosus, que foi coletado por Mahunka e Rohde Jr. (1970), no Irã.

Em Piracicaba/SP, os ácaros foram coletados durante quase todos os meses do ano, menos em dezembro e julho. Em Aquidauana/MS, essa espécie foi encontrada apenas nos meses de fevereiro, junho e outubro, enquanto em Capão do Leão/RS, foi coletado nos meses de janeiro e fevereiro.

$\mathrm{O}$ maior número de espécimes de $P$. bicormutus encontrado em um espécime de A. lividus em Piracicaba/SP, foi 05 espécimes, que estavam localizados na base das coxas do primeiro par de pernas do besouro. A capacidade própria de dispersão desse ácaro, deve ser bastante restrita, pois sua forma de locomoção é por caminhamento, e nesse contexto os besouros coprófagos, podem ser importantes agentes de dispersão para os ácaros. Os besouros por possuirem habilidade de voar, podem facilmente deslocar e explorar outros ambientes, e desta forma estão também auxiliando na dispersão do ácaro. Os ácaros dessa família utilizam os besouros apenas como agentes de dispersão, não causando portanto, nenhum dano aos mesmos. Como os ácaros foram encontrados nas três áreas estudadas, sem dúvida a forese que praticam sobre os besouros, auxilia em muito em sua dispersão para os diferentes ambientes.

Besouros como Aphodius lividus, com os quais P. bicornutus estava associado, já foram registrados em Piracicaba/SP (Rodrigues \& Marchini, 1998), Ilha Solteira/SP (Flechtmann et al., 1995b), Pereira Barreto/SP (Rodrigues \& Flechtmann, 1995), São Carlos/SP (Oliveria et al., 1996), Pirassununga/SP (Ruiz Diaz et al., 1999), Jaraguá do Sul/SC (Flechtmann \& Rodrigues, 1995), Selvíria/MS (Flechtmann et al., 1995d) e Campo Grande/MS (Koller et al., 1999). Na Argentina próximo à Buenos Aires, esse besouro também já foi coletado (Mariategui \& Speicys, 1997). É possível que em alguns locais onde o besouro ocorra o ácaro também possa estar presente. Para tanto há necessidade de se realizar coletas para se confirmar a sua ocorrência, haja vista que em Aquidauana/MS, nenhum espécime de Pygmodispus bicornutus foi encontrado associado a A. lividus. 
Apesar de P. bicormutus, ter sido coletado em Digitonthophagus gazella, em Aquidauana/MS, esse besouro não é de ocorrência natural do Brasil, pois foi importado pela Empresa Brasileira de Pesquisa Agropecuária - Centro Nacional de Pesquisa de Gado de Corte (EMBRAPA-CNPGC), para Campo Grande/MS (Honer et al., 1987; Bianchin et al., 1992), onde foi criado em laboratório e enviado para várias regiões do país. Portanto, na maioria dos locais onde ocorre, foi introduzido por pesquisadores, e desta forma o ácaro que ocorre no campo pouco utilizou desse hospedeiro para deslocamento e dispersão.

$\mathrm{Na}$ família Scutacaridae outros espécimes do gênero Pygmodispus utilizam os insetos como agentes de dispersão. Pygmodispus (Allodispus) brachiosus (Paoli ${ }^{4}$ citado por Ebermann, 1997a) foi encontrado praticando forese sobre Copris sp. (Coleoptera, Scarabaeidae). Ebermann (1998), em seus estudos observou a ocorrência de Imparipes schusteri, nas Ilhas Galapagos e distribuição neotropical (Mexico, El Salvador e Brasil); o autor ainda relata que a ocorência desse ácaro nessas localidades, evidencia que a forese é um importante fator na sua dispersão. Ebermann (1988) descreveu Imparipes (Imparipes) pselophidorum, associado com um besouro da família Pselaphidae (Centrophthalmus sp.). Cita ainda, que de 137 espécies do gênero Imparipes, 60 são conhecidas por praticar forese ou se associarem com artrópodos. Fain et al. (1995a), encontraram Archidispus bembidii associado com besouros da família Carabidae (Bembidion obliquum).

Alguns estudos desenvolvidos sobre comportamento de Pygmodispus sp., foram realizados e, dentre eles Ebermann (1991a), verificou que em alguns espécimes há o comportamento de retração das pernas e permanência imóvel, em fềmeas durante no máximo 6 minutos e 20 segundos. Esse comportamento é entendido como uma adaptação, que tem como resultado, um mecanismo passivo de defesa contra predadores.

\footnotetext{
${ }^{4}$ Paoli, G. Monografia dei Tarsonemidi. Redia. 7:215-281, 1911.
} 


\section{Scutacarus longitarsus (Berlese)}

Em Piracicaba/SP, foi encontrado um espécime de Scutacarus longitarsus, sob os élitros de Aphodius lividus. O ácaro coletado é uma fềmea forética e, utiliza o besouro hospedeiro apenas como agente de dispersão.

Nessa espécie de ácaro, já foi observado a ocorrência de polimorfismo nas fềmeas. Ebermann (1990), ao estudar o polimorfismo em espécies de Scutacaridae, verificou que $S$. fimetarius foi descrito a partir de uma fêmea forética, enquanto que $S$. subfimetarius foi descrito baseado em uma fêmea não forética. Ambas as espécies, são sinônimos de $S$. longitarsus. No caso de fềmeas que praticam forese, observa-se alterações morfológicas em seu corpo, o que teve como consequência descrições de novas espécies.

Samsinak (1989), coletou S. longitarsus de Leptocera fontinalis (Diptera; Sphaeroceridae), nos Estados Unidos, e sobre Leptocera (Rachispoda) cilifera na Slovakia.

Ebermann (1991b) observou polimorfismo em fềmeas também na família Scutacaridae, mas do gênero Archidispus. Nesse caso o autor estudou as espécies Archidispus minor e A. magnificus, e verificou que as fềmeas foréticas diferem morfologicamente de fềmeas não foréticas, pois as características morfológicas e etológicas são adaptações do comportamento forético.

\section{Scutacarus sp. Gros}

Esse ácaro foi coletado apenas em Capão do Leão/RS, e foi encontrado associado com Ataenius sp1, Ataenius sp2 e Ataenius sp3 (Tabela 4.1).

Os ácaros utilizam várias regiões do corpo dos besouros para se fixarem, como nos pêlos localizados na base e entre as coxas do primeiro par de pernas, nos palpos labiais, na base das antenas e nas várias regiões do tórax e abdome.

No gênero Scutacarus são conhecidas mais de 200 espécies distribuidas pelo mundo (Metwali, 1984). A associação de espécies de Scutacarus com artrópodos, já foi encontrada por alguns pesquisadores. As espécies Scutacarus (Scutacarus) unicosimilis 
e Scutacarus $(S$.$) wisniewskii, foram encontradas associadas a ninhos de formigas da$ espécie Cataglyphus bicolor, no Egito, por Metwali (1984).

Scutacarus baculitarsus foi encontrado associado com Megaselia halterata (Diptera, Phoridae) (Binns, 1979). Esse ácaro apresenta o comportamento de posicionarse apenas sobre o quarto par de pernas e os demais ficarem suspensos (posicionamento quase vertical em relação a superficie de contato), na tentativa de se fixarem ao inseto hospedeiro, para se dispersarem.

Delfinado \& Baker (1976) encontraram vários ácaros do gênero Scutacarus associados com Hymenoptera: Scutacarus (Scutacarus) impar e S. (S.) subspinosus estavam em ninhos de Blarina brevicauda; Scutacarus (S.) spinosus em ninho de Microtus pennsylvanicus e Scutacarus (S.) eickworti em ninho de Dialictus nymphaearum.

\subsubsection{Familia Pygmephoridae}

\section{Elattoma sp1. Mahunka}

Em Aquidauana/MS esse ácaro foi encontrado associado apenas com Digitonthophagus gazella, e em Piracicaba/SP estava associado com Aphodius lividus e Dichotomius bos, sendo que dos 565 espécimes coletados, 564 estavam em D. bos (Tabela 4.2).

Em Aquidauana/MS, os ácaros foram coletados apenas no mês de junho, enquanto que em Piracicaba/SP, foram encontrados nos meses de janeiro, fevereiro, março, outubro e dezembro.

Em um único espécime de D. bos, foram encontrados 176 espécimes de Elattoma spl, sendo que, 96 ácaros estavam localizados na membrana intersegmental entre o protórax e o pterotórax, e 80 no esterno do pterotórax. Em outro espécime de D. bos, foram encontrados 168 ácaros localizados na membrana intesegmental entre o protórax e o pterotórax. 
Dentre as regiões do corpo dos besouros onde os ácaros foram encontrados, observa-se que na membrana intersegmental entre o protórax e pterotórax é o principal local de fixação dos ácaros, onde foram encontrados 425 espécimes, representando $75,22 \%$ do total de ácaros coletados. $\mathrm{Na}$ região do esterno do pterotórax, foram encontrados 100 espécimes representando $17,70 \%$ do total de ácaros coletados, e no abdome foram encontrados 40 espécimes representando $7,08 \%$ do total de ácaros coletados.

Os espécimes de ácaros coletados sobre os besouros são fềmeas, e estão utilizando-os apenas como agentes de dispersão, praticando forese. Devido o comportamento forético que os ácaros praticam sobre artrópodos, levou Moser \& Cross (1975), a estudarem o fato de que poderia ocorrer diferenças morfológicas dentro de uma mesma espécie de Pygmephoridae. Como resultado, verificaram que uma mesma espécie de ácaro pode apresentar diferenças morfológicas, quando praticam forese. Nesse contexto verificaram a existência de quatro tipos diferentes de ácaros que praticam forese. Assim criaram um quinto tipo, o qual denominaram de foretomorfo, designando-o para as fêmeas de ácaros especializados em praticar forese. Como consequência da forese, ácaros de uma mesma espécie foram descritos em gêneros distintos (Siteroptes (fềmea normal) e Pediculaster (fềmea foretomorfo); Siteroptes (fềmea normal) e Pygmephorellus (fêmea foretomorfo)).

Fêmeas foretomórficas foram encontradas também por Smiley (1978), ao estudar os ácaros do gênero Pygmephorus (Pygmephoridae).

Como o espécime de Elattoma spl, foi coletado de um besouro coprófago, é possível que ocorra para essa espécie, adultos não foréticos e consequentemente com morfologia distinta dos coletados sobre os besouros.

Savulkina (1981) verificou a existência de quatro espécies do gênero Elattoma. E alguns podem utilizar besouros como agentes de dispersão. Os ácaros desse gênero foram registrados na Alemanha, Brasil e Chile. 


\section{Elattoma sp2. Mahunka}

Um único exemplar desse ácaro foi coletado em Capão do Leão/RS, no mês de janeiro, e estava associado com Ataenius sp1 (Tabela 4.2), localizado na base das coxas do primeiro par de pernas do besouro.

Dastych \& Rack (1993b), descreveram o gênero Spatulaphorus; o qual apresenta algumas características dos gêneros Elattoma e Pygmephorellus. Esses autores descreveram Spatulaphorus camerikae, o qual estava associado com Catharsius ulysses (Coleoptera, Scarabaeidae), Spatulaphorus langi foi descrito e estava localizado nos élitros de Catharsius sp. e Spatulaphorus foliatus foi encontrado associado com Onitis sp. (Coleoptera, Scarabaeidae).

\section{Bakerdania sp1. Sasa}

Em Piracicaba/SP esse ácaro foi encontrado nos meses de fevereiro, abril, maio, setembro e novembro associado apenas com Aphodius lividus. Em Capão do Leão/RS, foi encontrado associado com Ataenius spl (Tabela 4.2), durante o mês de fevereiro.

Os ácaros coletados são fềmeas, que utilizam os besouros como agentes de dispersão e, foram encontrados localizados na base das coxas do primeiro par de pernas dos besouros.

Alguns espécimes de ácaros desse gênero já foram encontrados associados com artrópodos: Bakerdania sellnicki foi encontrado associado com besouros da família Scolytidae por Moser \& Roton (1971); Bakerdania sp. nr. cultratus foi encontrado por Olynyk \& Freitag (1979), associado com coleópteros da família Carabidae.

Além dos insetos, podem aparecer associados com plantas. Rack \& Kaliszewski (1985) encontraram as espécies Bakerdania dracenae e Bakerdania vandaeli associados com plantas ornamentais na Bélgica.

Savulkina (1981) verificou que os ácaros do gênero Bakerdania podem aparecer em ninhos de pequenos mamíferos, pássaros e associados com insetos. No mundo são conhecidas cerca de 121 espécies do gênero Bakerdania. 


\section{Bakerdania sp2. Sasa}

Em Aquidauana/MS esse ácaro foi coletado de Digitonthophagus gazella e Ataenius spl; em Piracicaba/SP, foi encontrado em Aphodius lividus e Dichotomius bos, e em Capão do Leão/RS, com Aphodius lividus (Tabela 4.2).

Em Aquidauana/MS, esse ácaro foi coletado nos meses de fevereiro e setembro, em Piracicaba/SP, foi encontrado nos meses de fevereiro, março e setembro e em Capão do Leão/RS, no mês de fevereiro.

Bakerdania sp2, foi o único ácaro coletado nas três localidades estudadas, e foi também o ácaro que apresentou o maior número de besouros hospedeiros, na família Pygmephoridae, demonstrando assim não apresentar preferência hospedeira. Cudmore et al. (1987) e Whitaker Jr. et al. (1982), encontraram baixo grau de especificidade hospedeira, em espécies de Pygmephorus, que aparecem associados com mamíferos. É possível que seja uma característica da família, a não especificidade ou não preferência hospedeira.

Kaliszewski \& Rack (1985) encontraram Pygmephorus sylvilagus associado com insetos da família Leporidae e Pygmephorus erlangensis associado com insetos da família Gliridae.

Kaliszewski (1988b) encontrou Pseudobakerdania extrema em amostras de solo da Sibéria e Pseudobakerdania occulta em amostras de solos na Polônia.

\section{Sicilipes sp. Cross}

Esse ácaro foi coletado apenas em Capão do Leão/RS, nos meses de janeiro e fevereiro, e estava associado com Ataenius sp1 e Ataenius sp2 (Tabela 4.2).

Dos 67 espécimes de ácaros coletados em Capão do Leão/RS, Sicilipes sp., representou 95,52\% (64 espécimes), do total de ácaros coletados (Tabela 4.2).

\section{Elattosoma sp. Mahunka}

Essa espécie de ácaro foi encontrado em Aquidauana/MS, nos meses de fevereiro, março, junho, agosto e setembro. Estava localizado na base das coxas do primeiro par de pernas de Ontherus appendiculatus e Ontherus sulcator (Tabela 4.2). 


\section{Pediculaster sp. near brasiliensis Mahunka}

O referido ácaro foi coletado em Piracicaba/SP e estava associado com Aphodius lividus (Tabela 4.2). Os ácaros coletados eram fêmeas foréticas, utilizam os besouros como agentes de dispersão e, estavam localizados na base das coxas do primeiro par de pernas dos besouros.

No gênero Pediculaster, os ácaros podem utilizar vários tipos de artrópodos como agentes de dispersão. Várias espécies foram encontradas associadas com dípteros da família Sphaeroceridae: Pediculaster norrbomi estava associado com Leptocera fontinalis; Pediculaster malyi com Leptocera (Rachispoda) cilifera; Pediculaster costaricensis, com Parasphaerocera tertia e Pediculaster rysanovy com Leptocera (s. str.) nigra (Samsinak, 1989).

Camerik \& Coetzee (1998) coletaram Pediculaster copridis em fezes de bovinos e em fezes de eqüinos. Esse ácaro foi encontrado também associado com Musca confiscata (Diptera: Muscidae) e Norrbomia marginatis (Diptera: Sphaeroceridae). Pediculaster luriei, além de estar associado aos mesmos tipos de fezes e dípteros de $P$. copridis, foi encontrado ainda associado com outros insetos das famílias Muscidae, Sepsidae, Scarabaeidae (Aphodius spp.), Staphilinidae e outros besouros.

Para os ácaros da família Pygmephoridae, as áreas sob os élitros dos besouros não são um microhabitat importante, para utilizarem durante o período em que praticam forese, pois nenhum ácaro foi encontrado nessa região do corpo dos besouros.

Com o presente trabalho, pode-se concluir que os ácaros das familias Scutacaridae e Pygmephoridae, utilizam os besouros coprófagos apenas para se dispersarem praticando assim sobre eles a forese. 
Tabela 4.1. Relação de espécies e número de ácaros da família Scutacaridae, associados com besouros coprófagos, coletados em Aquidauana/MS (durante o período de agosto de 1998 a agosto de 1999), Piracicaba/SP (durante o período de agosto de 1997 a agosto de 1998) e Capão do Leão/RS (durante o período de dezembro de 1997 a fevereiro de 1998).

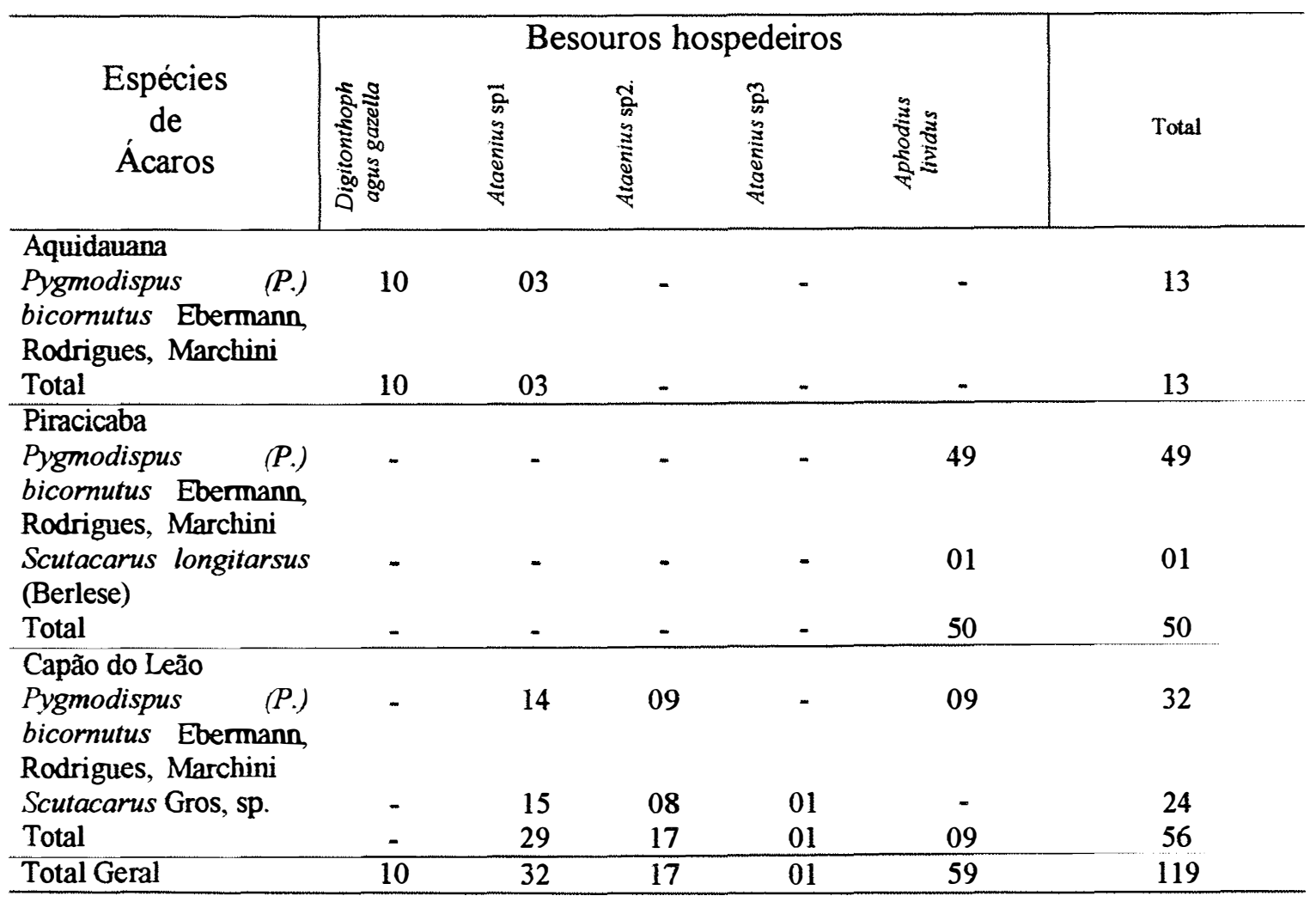


Tabela 4.2. Relação de espécies e número de ácaros da família Pygmephoridae, associados com besouros coprófagos, coletados em Aquidauana/MS (durante o período de agosto de 1998 a agosto de 1999), Piracicaba/SP (durante o período de agosto de 1997 a agosto de 1998) e Capão do Leão/RS (durante o período de dezembro de 1997 a fevereiro de 1998).

\begin{tabular}{|c|c|c|c|c|c|c|c|c|}
\hline \multirow[b]{2}{*}{ Espécies } & \multicolumn{7}{|c|}{ Besouros hospedeiros } & \multirow[b]{2}{*}{ Total } \\
\hline & 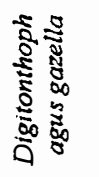 & 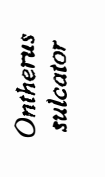 & 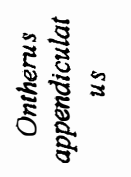 & 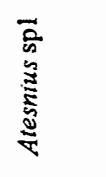 & 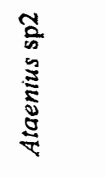 & 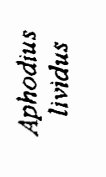 & 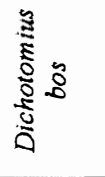 & \\
\hline \multicolumn{9}{|l|}{ Aquidauana } \\
\hline Elattoma spl, Mahunka & 09 & - & - & - & - & - & - & 09 \\
\hline Bakerdania sp2 Sasa & 05 & - & - & 01 & - & - & - & 06 \\
\hline Elattosoma, Mahunka & - & 06 & 13 & - & - & - & - & 19 \\
\hline Total & 14 & 06 & 13 & 01 & - & - & - & 34 \\
\hline \multicolumn{9}{|l|}{ Piracicaba } \\
\hline Elattoma sp1, Mahunka & - & - & - & - & - & 01 & 564 & 565 \\
\hline Bakerdania spl Sasa & - & - & - & - & - & 16 & - & 16 \\
\hline Bakerdania sp2 Sasa & - & - & - & - & - & 05 & 03 & 08 \\
\hline $\begin{array}{l}\text { Pediculaster sp. near } \\
\text { brasiliensis Mahunka }\end{array}$ & - & - & - & - & - & 02 & - & 02 \\
\hline Total & - & - & - & - & - & 24 & 567 & 591 \\
\hline \multicolumn{9}{|l|}{ Capão do Leão } \\
\hline Elattoma sp2, Mahunka & - & - & - & 01 & - & - & - & 01 \\
\hline Bakerdania spl Sasa & - & - & - & 01 & - & - & - & 01 \\
\hline Bakerdania sp2 Sasa & - & - & - & - & - & 01 & - & 01 \\
\hline Sicilipes sp, Cross & - & - & - & 53 & 11 & - & - & 64 \\
\hline Total & - & - & - & 55 & 11 & 01 & - & 67 \\
\hline Total Geral & 14 & 06 & 13 & 56 & 11 & 25 & 567 & 692 \\
\hline
\end{tabular}




\section{5 ÁCAROS (ACARI) ASSOCIADOS AOS BESOUROS COPRÓFAGOS (COLEOPTERA， SCARABAEIDAE): EVIPHIDIDAE, PARASITIDAE, LAELAPIDAE, PACHYLAELAPIDAE, UROPODIDAE (MESOSTIGMATA), ACARIDAE E ANOETIDAE (ASTIGMATA).}

\subsection{Introdução}

Várias são as espécies de ácaros que podem ocorrer associados aos besouros coprófagos segundo Costa (1969) e Halffter \& Matthews (1971).

Muitos desses ácaros aparecem associados aos besouros coprófagos, apenas praticando forese e, segundo Athias-Binche et al. (1993) a dispersão forética pode ser vital para os ácaros.

Deutoninfas e adultos de várias famílias de ácaros tem estabelecido relacionamento forético com artrópodos, incluindo Parasitidae, Laelapidae, Eviphididae, Macrochelidae, Uropodidae, Acaridae e Anoetidae (Krantz, 1978).

O presente trabalho teve por objetivos verificar quais espécies de ácaros das familias, Parasitidae, Eviphididae, Laelapidae, Pachylaelapidae, Acaridae, Anoetidae e Uropodidae ocorrem associados com os besouros coprófagos. 


\subsection{Material e Métodos}

\subsubsection{Coleta de besouros coprófagos e extração de ácaros}

Para realizar a coleta de besouros coprófagos foram utilizadas 4 armadilhas "pitfall" iscadas com massa fecal fresca de bovinos, instaladas em áreas de pastagem na Universidade de São Paulo (ESALQ/USP) em Piracicaba/SP e, na Universidade Estadual de Mato Grosso do Sul (UEMS), no município de Aquidauana/MS. Com uso de armadilha luminosa, instalada ao lado de área de pastagem na Fazenda Experimental da Empresa Brasileira de Pesquisa Agropecuária - Centro de Pesquisa Agropecuária de Clima Temperado (EMBRAPA-CPACT), em Capão do Leão/RS, realizou-se também a coleta de besouros coprófagos.

O uso de armadilhas "pitfall" tem sido empregada em estudos onde avalia-se a distribuição e comportamento populacional de besouros coprófagos (Lobo et al., 1988). A armadilha "pitfall" consiste de um tripé de metal com cerca de $28 \mathrm{~cm}$ de altura, ao qual dependura-se um volume de cerca de $700 \mathrm{ml}$ de massa fecal fresca de bovino, envolta em tecido de voal. Imediatamente sob a massa, são colocados dois copos plásticos, um encaixado dentro do outro, de $350 \mathrm{ml}$ de volume, enterrados ao nível do solo, e preenchido com água e detergente.

Após 24 horas da instalação da armadilha "pitfall", os insetos coletados eram retirados e na semana seguinte as armadilhas eram reinstaladas. Estas atuaram no período de agosto de 1997 a agosto de 1998 em Piracicaba/SP, e de agosto de 1998 a agosto de 1999 em Aquidauana/MS.

A armadilha luminosa permanecia durante a noite coletando os insetos, e na manhã do dia seguinte da instalação realizava-se a coleta dos besouros, acondicionandoos em álcool, anotando-se a data de coleta. Com essa armadilha foram realizadas 48 coletas de besouros coprófagos, durante o período de dezembro de 1997 a fevereiro de 1998. 
A armadilha luminosa é um dos métodos mais tradicionalmente utilizados no levantamento populacional de insetos (Gallo et al., 1988), utilizada também para coleta de besouros coprófagos (Flechtmann et al., 1995c).

Após a triagem e identificação dos besouros, realizou-se a extração dos ácaros presentes nestes. Para a localização dos ácaros inicialmente os apêndices móveis dos besouros eram retirados do resto do corpo, e posteriormente destacava-se a cabeça do tórax e o abdome do tórax. Com o inseto fragmentado podia-se facilmente localizar os ácaros. Antes de serem montados, os ácaros foram acondicionados em solução de Vitzthum, e transferidos para estufa a $45^{\circ} \mathrm{C}$ por 48 horas para a clarificação. Em seguida foram transferidos para lâminas de montagem em meio de Hoyer's, onde permaneciam por 7 dias em estufa a $45^{\circ} \mathrm{C}$.

Os ácaros foram depositados na Universidade Estadual de Mato Grosso do Sul em Aquidauana (UEMS).

\subsection{Resultados e Discussão}

\section{Eviphididae}

Os ácaros dessa família foram coletados em Piracicaba/SP, associados com Dichotomius bos e Aphodius lividus, em Aquidauana/MS, foram encontrados associados com D. bos e Ontherus appendiculatus (Tabela 5.1). Os ácaros encontrados utilizam os besouros apenas como agentes de dispersão.

Algumas espécies de Eviphididae foram encontradas por alguns pesquisadores associados com besouros coprófagos. Takaku (1997) redescreveu Eviphis cultratellus e verificou que esse ácaro mantém associação com alguns besouros coprófagos como Geotrupes auratus, Copris ochus, Onthophagus lenzii e Liatongus phanaeoides. Os ácaros foram encontrados na superficie do corpo dos besouros hospedeiros.

Costa (1969) relata que cerca de 39 espécies de ácaros da família Eviphididae ocorrem associadas com insetos, sendo que destes, 36 ocorrem associados com besouros 
coprófagos. Os estágios que ocorrem associados são, machos, fêmeas, deutoninfas e, raramente larva e protoninfa.

Halffter \& Matthews (1971) realizaram uma revisão de literatura onde estudaram os vários organismos que mantêm associação com os besouros coprófagos verificando a existência de várias espécies de ácaros da família Eviphididae associadas com besouros coprófagos.

Masan (1994) encontrou vários ácaros da família Eviphididae associados com besouros das famílias Scarabaeidae e Silphidae. Christie (1983) descreveu Alliphis necrophilus que estava associado com um besouro da familia Silphidae (Nicrophorus vespilloides).

\section{Parasitidae}

Em Aquidauana/MS, foram coletadas três prováveis espécies dessa familia: Parasitus sp 1, estava associada com D. bos, Ontherus appendiculatus, Digitonthophagus gazella, Onthophagus hirculus e Ataenius sp.; Parasitus sp2 e Parasitus sp3, estavam associados com Ontherus appendiculatus (Tabela 5.1).

Em Piracicaba/SP, Parasitus sp1, foi encontrado associado com Dichotomius bos e Aphodius lividus e em Capão do Leão/RS, Parasitus sp2, com Aphodius lividus (Tabela 5.1).

$\mathrm{Na}$ grande maioria das vezes os ácaros foram coletados sob os élitros dos besouros coprófagos. Sob os élitros de Aphodius lividus, a máxima quantidade de ácaros encontrados foram seis deutoninfas de Parasitus sp 1.

Vários pesquisadores verificaram a associação de ácaros dessa família como, Parasitus coleoptratorum e P. fimetorum em besouros coprófagos (Wallace \& Holm, 1985). Esses ácaros apareceram associados com algumas espécies de besouros coprófagos do gênero Onthophagus. Parasitus coleoptratorum é mais ativo durante a primavera e verão e $P$. fimetorum é mais ativo durante o período compreendido entre a primavera até o outono. 
Samsinak \& Daniel (1978) descreveram Parasitus himalayanus que estava associado com Geotrupes tenebrosus e G. castaneipennis.

Costa (1969) relata que 8 espécies de ácaros da familia Parasitidae ocorrem associadas com besouros coprófagos. Podem ainda ocorrer associados com besouros da familia Silphidae, abelhas e vespas. A fase que ocorre associado aos insetos são as deutoninfas e, Parasitus copridis foi encontrado praticando forese sobre Copris hispanus.

Além de viverem associados com alguns besouros coprófagos os ácaros da familia Parasitidae, podem ser importantes predadores de ovos e larvas de moscas, que desenvolvem-se nas fezes, como a espécie Poecilochirus monospinosus (Wise et al., 1988).

Brown \& Wilson (1992) verificaram que Poecilochirus carabi tem preferência por algumas espécies de besouros da familia Silphidae, do gênero Nicrophorus, para praticar forese. A preferência por determinada espécie de besouro, está relacionada a atividade reprodutiva do besouro hospedeiro.

Alguns ácaros do gênero Parasitus podem predar estágios imaturos de moscas que causam danos em cogumelos, como observado para Parasitus bituberosus (Al-Amidi et al., 1991).

Schousboe (1987) verificou a presença de quatro espécies de Parasitellus praticando forese sobre Bombus terrestris e Bombus lucorum. Lundqvist \& Micherdzinski (1975) redescreveram Parasitus talparum e encontraram esse ácaro associado a ninhos de abelhas.

\section{Laelapidae}

Foram coletados duas espécies de Laelapidae, associados com besouros coprófagos. A espécie Laelapidae spl, foi encontrado associado com Dichotomius bos, Ontherus appendiculatus e Digitonthophagus gazella em Aquidauana/MS. Nessa localidade foram encontrados 80 Laelapidae sp1, sob os élitros de $D$. gazella, sendo que 
esse foi o maior número do ácaro presente no corpo de um besouro. Sob os élitros de $D$. bos o maior número do ácaro encontrado foi 50 espécimes. Em Aquidauana/MS foi coletado ainda Laelapidae sp2, encontrado associado com Ontherus sulcator (Tabela $5.1)$.

Em Piracicaba/SP, Laelapidae spl foi encontrado associado com Dichotomius bos. O máximo número desse ácaro sob os élitros do besouro foi 18 (Tabela 5.1).

Halffter \& Matthews (1971) realizaram uma revisão de literatura onde estudaram vários organismos que mantêm associação com os besouros coprófagos, verificando a existência de uma espécie de ácaro da família Laelapidae associada com uma espécie de besouro coprófago.

Nessa família os ácaros podem estar associados com outros artrópodos, pois, Royce \& Krantz (1989) encontraram Pneumolaelaps longanalis (Laelapidae) associado com abelhas (Bombus occidentalis). Alguns podem ainda ser predadores pois, Wright \& Chambers (1994) estudaram a biologia de Hypoaspis miles (Laelapidae), que é um importante predador de Bradysia paupera (Diptera: Sciaridae).

\section{Pachylaelapidae}

Uma espécie de Pachylaelapidae foi encontrada em Aquidauana/MS, associada com Dichotomius bos e Digitonthophagus gazella, já em Piracicaba/SP, foi encontrada em Dichotomius bos e Aphodius lividus (Tabela 5.1). Esse ácaro foi encontrado na região gular e na base das coxas do primeiro par de pernas dos besouros coprófagos.

Halffter \& Matthews (1971) realizaram uma revisão de literatura onde estudaram os vários organismos que mantêm associação com os besouros coprófagos, e verificaram a existência de várias espécies de ácaros da família Pachylaelapidae associadas com besouros coprófagos.

Costa (1969) relata que são conhecidas 18 espécies de ácaros da família Pachylaelapidae, que aparecem associadas com besouros coprófagos. 


\section{Acaridae}

Os ácaros coletados são estágios imaturos chamados de "hipopus" e utilizam os besouros como agentes de dispersão. Várias são as regiões do corpo dos besouros onde os ácaros podem se fixar, como nos palpos labiais, na base das antenas, na base dos olhos compostos, na região gular, nas várias regiões das pernas, sobre e sob os élitros, no tórax e abdome.

Os ácaros encontrados pertencem a espécie Sancassania (=Caloglyphus) sp. near chelone. Em Aquidauana/MS, os besouros com os quais estava associado foram, Dichotomius bos e Digitonthophagus gazella e em Piracicaba/SP com Dichotomius bos, Aphodius lividus e Ataenius sp. (Tabela 5.2).

Flechtmann \& Alves (1976) encontraram "hipopus" de Acaridae associados com Dichotomius longiceps.

Além de aparecerem associados com besouros coprófagos, vários são os grupos de insetos com os quais os ácaros da família Acaridae podem manter associação.

Olynyk \& Freitag (1979) e Fain et al. (1995a), encontraram Sancassania sp. associados com coleópteros da família Carabidae. Samsinak (1989) encontrou uma espécie de Acaridae (Calvolia marie) associado com um díptero da família Sphaeroceridae (Gymnometopina magna).

Fain \& Chmielewski (1987) encontraram Tyrophagus formicetorum em ninho de formiga (Formica rufa) e Lasioacarus nidicolus em ninho de formigas (Lasius niger).

Furniss et al. (1972) verificaram que "hipopus" de Histiogaster arborsignis (Acaridae) são foréticos sobre besouros da família Scolytidae.

\section{Anoetidae (= Histiostomatidae)}

Esse ácaro foi coletado em AquidauanaMS e Capão do Leão/RS na fase de deutoninfas, e estavam associados com Aphodius lividus (Tabela 5.2).

Bongers et al. (1985) estudaram os ácaros da família Anoetidae, que ocorrem em fezes bovinas e associados com besouros coprófagos na Holanda. Encontraram 
Aphodanoetus teinophallus, associado com Aphodius frater (Scarabaeidae), Histiostoma phyllophorum em Aphodius fimetarius (Scarabaeidae) e Rhopalanoetus fimetarius em Aphodius fimetarius e Teuchestes fossor (Scarabaeidae).

Bongers et al. (1985) afirmam que os ácaros da família Anoetidae (citados como Histiostomatidae), contribuem para a decomposição de fezes bovinas em áreas de pastagens e são importantes predadores/parasitos de larvas de moscas que desenvolvemse nas fezes.

Os ácaros encontrados associados com os besouros coprófagos, utilizam os besouros apenas como agentes de dispersão, não causando nenhum dano aos mesmos.

Ácaros dessa família já foram encontrados associados com coleópteros das familias Carabidae (Olynyk \& Freitag, 1979; Fain et al., 1995a) e Scolytidae (Moser \& Roton, 1971; Stephen \& Kinn, 1980) e, com dípteros da família Sphaeroceridae (Samsinak, 1989).

\section{Uropodidae}

Em Aquidauana/MS esse ácaro foi encontrado associado com Dichotomius bos, D. nisus, Digitonthophagus gazella e Ataenius sp. e em Piracicaba/SP, com Aphodius lividus (Tabela 5.2).

O máximo número de Uropodidae encontrado foi 30 espécimes em D. nisus, localizados nas coxas do primeiro par de pernas.

Flechtmann \& Alves (1976) encontraram ninfas de Uropodidae associadas com Dichotomius camporum, Dichotomius crinicollis, Diabroctis mimas e Phanaeus (Megaphanaeus) ensifer.

Algumas espécies de Uropodidae foram encontradas associadas com besouros coprófagos por Wisniewski \& Hirschmann (1996): Uropoda afghanica foi encontrado em Homalocopris tmolus, Uropoda americana em Copris sp., Uropoda mediterranea em Copris hispanicus e Uropoda shanghaica em besouros escarabeideos da tribo Coprini. 
Várias espécies de ácaros da familia Uropodidae, foram encontradas associadas com diferentes grupos de insetos.

Athias-Binche et al. (1993) verificaram que Neoseius novus são foréticos sobre Necrophorus spp. (Coleoptera: Silphidae), e deutoninfas de Uropodidae foram encontradas por Rubink et al. (1991) associadas com Apis mellifera praticando forese.

Associadas com formigas, algumas espécies de Uropodina foram encontradas por Elzinga (1995); Trichocylliba gibbata foi encontrada associada com Neivamyrmex gibbatus, Trichocylliba morosa em Cheliomyrmex morosus, Trichocylliba agnesae em Labidus praedator, Trichocylliba tumba em Eciton burchelli e Trichocylliba neili em Labidus coecus.

Gordh \& Wills (1989) encontraram 189 deutoninfas de Uropoda sp. fixadas em Alphitobius diaperinus (Tenebrionidae). Esses ácaros apresentam um pedúnculo anal, que permite que o ácaro permaneça fixado ao besouro hospedeiro.

Para o presente trabalho pode-se concluir que os ácaros coletados aparecem associados aos besouros coprófagos praticando forese. 
Tabela 5.1. Relações e números de ácaros das familias Eviphididae, Parasitidae, Laelapidae e Pachylaelapidae associados com besouros coprófagos coletados em área de pastagem em Aquidauana/MS (de agosto de 1998 a agosto de 1999), Piracicaba/SP (de agosto de 1997 a agosto de 1998) e Capão do Leão/RS (Dezembro de 1997 a Fevereiro de 1998).

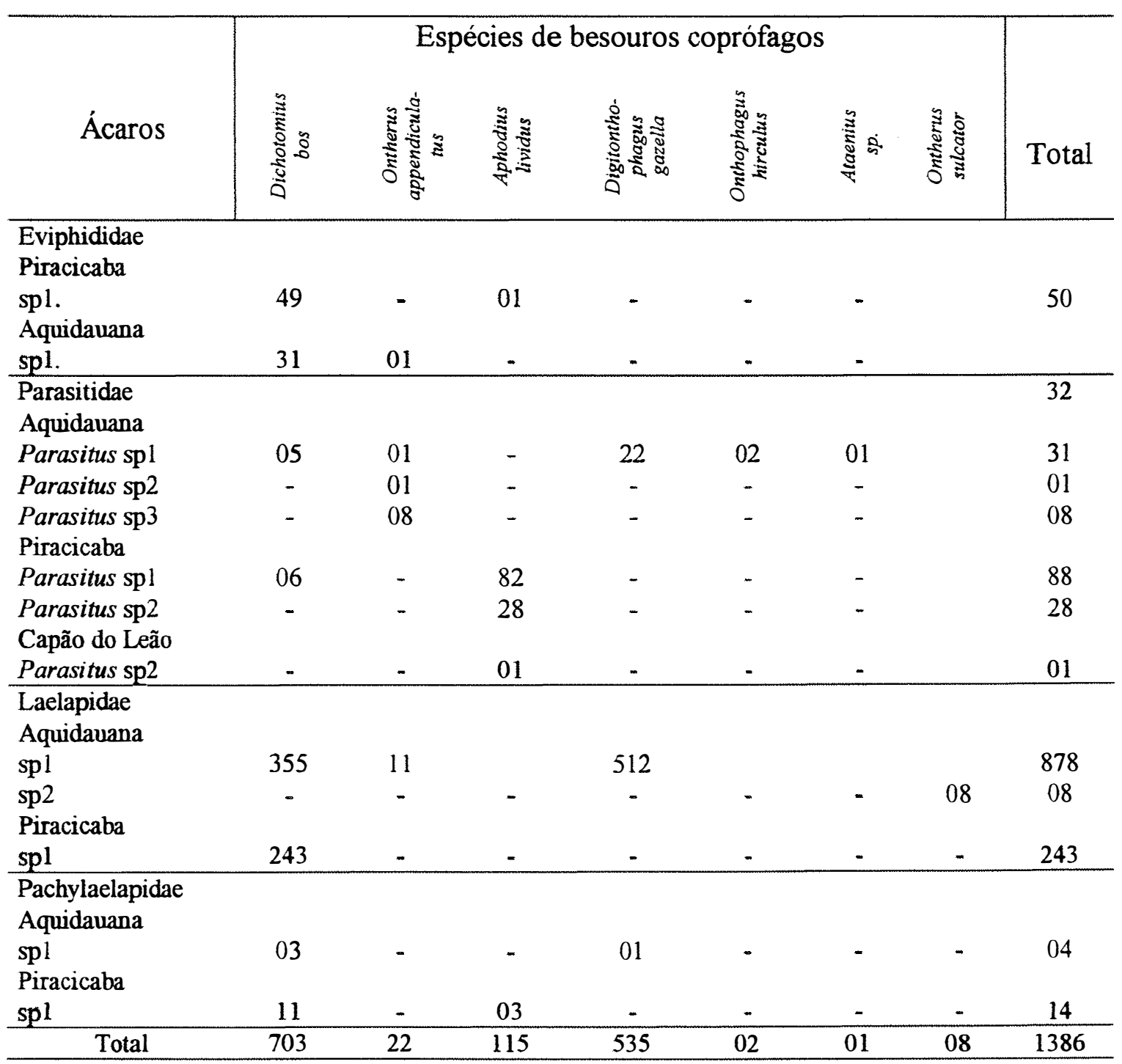


Tabela 5.2. Relações e números de ácaros das famílias Acaridae, Anoetidae e Uropodidae associados com besouros coprófagos coletados em área de pastagem em Aquidauana/MS (de agosto de 1998 a agosto de 1999), Piracicaba/SP (de agosto de 1997 a agosto de 1998) e, Capão do Leão/RS (Dezembro de 1997 a Fevereiro de 1998).

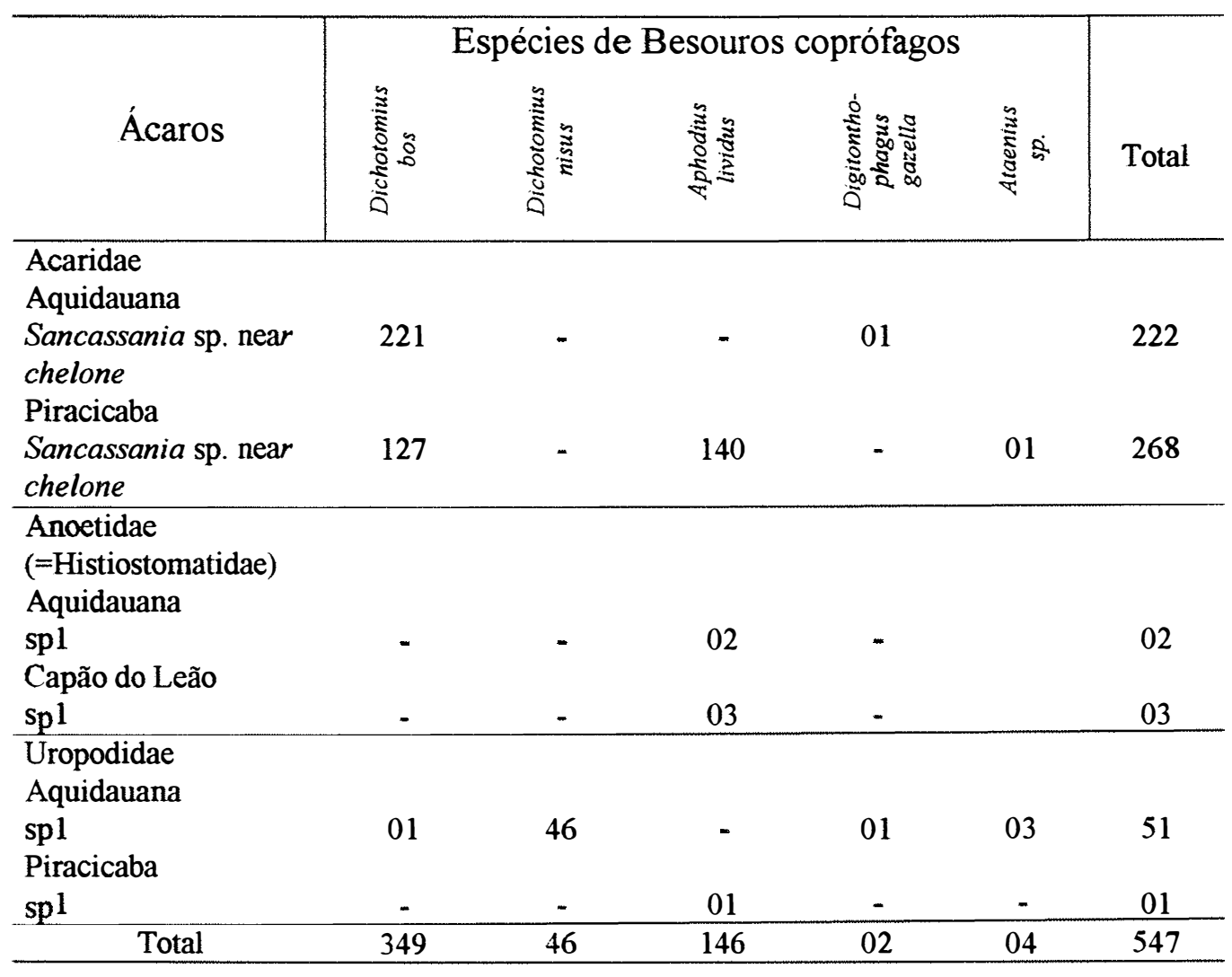




\section{CONCLUSÕES}

1. Os besouros coprófagos são importantes agentes de dispersão para os ácaros;

2. Em Aquidauana/MS foi encontrado maior diversidade de ácaros da família Macrochelidae;

3. Macrocheles merdarius e $M$. insignitus foram os ácaros que apresentaram o maior número de besouros hospedeiros;

4. A maioria das espécies de besouros utilizados pelos ácaros da família Scutacaridae para dispersão, possuem pequena biomassa;

5. Os ácaros da família Laelapidae permanecem sob os élitros dos besouros, para se dispersarem. 


\section{REFERÊNCIAS BIBLIOGRÁFICAS}

ADIS, J.; KRANTZ, G. W. Notes on the natural history of Macrocheles (Acari: Gamasida: Macrochelidae) associated with 3-toed sloths Bradypus spp. (Edentata: Bradypodidae) in the cental amazon. Zoologischer Anzeiger, v.214, n.3/4, p.222-224, 1985.

AL-AMIDI, A. H. K.; DUNNE, R.; DOWNES, M. J. Parasitus bituberosos (Acari: Parasitidae): An agent for control of Lycoriella solani (Diptera: Sciaridae) in mushroom crops. Experimental \& Applied Acarology, v.11, p.159-166, 1991.

ALVES, S. B. Biologia e importância econômica do Dichotomius anaglypticus (Mannerheim, 1829) (Coleoptera, Scarabaeidae). Piracicaba, 1977. 72p. Dissertação (Mestrado) - Escola Superior de Agricultura "Luiz de Queiroz", Universidade de São Paulo.

ALVES, S. B.; NAKANO, O. Influência do Dichotomius anaglypticus (Mannerheim, 1829) (Coleoptera, Scarabaeidae) no crescimento de plantas de napier. Ecossistema, v.2, n.2, p.31-33, 1977.

ATHIAS-BINCHE, F.; SCHWARZ, H. H.; MEIERHOFER, I. Phoretic association of Neoseius novus (Ouds., 1902) (Acari: Uropodina) with Necrophorus spp. (Coleoptera: Silphidae): A case of sympatric speciation? International Journal of Acarology, v.19, n.1, p.75-86, 1993. 
AXTELL, R. C. New records of north americam Macrochelidae (Acarina: Mesostigmata) and their predation rates on the house fly. Annals of The Entomological Society of America, v.54, p.748, 1961.

AXTELL, R. C. Acarina occurring in domestic animal manure. Annals of the Entomological Society of America, v.56, p.628-633, 1963.

BERLESE, A. Lista de nuove specie e nouvi generi di Acari. Redia, v.6, p.242-271, 1910.

BERLESE, A. 1911. Alguni Acari entomogili nuovi. Redia. In: HAMMER, L. VANDER. (Ed.). A. Berlese: Complete acarological works, Collected acarological papers previously published in Redia, 1903-1923. The hague: W. Junk; Lochem: Antiquariaat Junk, 1977. v.1 (1-15).

BERLESE, A. 1913. Acarotheca italica. Species exhibens repraesentantes genera in Italia magis communia, speciminibus asservatis, icone et descriptione illustratas; adiecta brevi synonimia et bibliographia generum et specierum. Fasciculi Ius et. Iius. Praemisso Acarorum systemate genera omnia in suas familias referenti. Redia. In: HAMMER, L. VANDER (Ed.). A. Berlese: complete acarological works, Varia, 1881-1923. The Hague: W. Junk; Amsterdam; Antiquariaat Junk, 1982, v.1.

BERLESE, A. 1917. Centuria seconda di Acari nuovi. Redia. In: HAMMER, L. VANDER. (Ed.). A. Berlese: complete acarological works, collected acarological papers previously published in Redia, 1903-1923. The Hague: W. Junk; Lochem : Antiquariaat Junk, 1977. v.5 (19 e 31).

BERLESE, A. Centuria quarta de Acari nuovi. Redia, v.13, p.113-190, 1918. 
BIANCHIN, I.; HONER, M. R.; GOMES, A. Controle integrado da mosca-dos-chifres na região Centro-Oeste. Hora Veterinária, v.11, p.43-46, 1992.

BINS, E. S. Scutacarus baculitarsus Mahunka (Acarina: Scutacaridae) phoretic on the mushroom phorid fly Megaselia halterata (Wood). Acarologia, v.21, n.1, p.91-107, 1979.

BONGERS, M. G. H.; O`CONNOR, B. M.; LUKOSCHUS, F. S. Morphology and ontogeny of histiostomatid mites (Acari: Astigmata) associated with cattle dung in the Netherlands. Zoologische Verhandelingen, n.223, p.1-56, 1985.

BROWN, J. M.; WILSON, D. S. Local specialization of phoretic mites on sympatric carrion beetle hosts. Ecology, v.73, n.2, p.463-478, 1992.

BRUSSAARD, L.; RUNIA, L. T. Recent and ancient traces of scarab beetles activity in sandy soils of Netherlands. Geoderma, v.34, n.3/4, p.229-250, 1984.

BRYAN, R. P. Effects of dung beetles activity in the numbers of parasitic gastrointestinal helminth larvae recovered from pasture samples. Australian Journal of Agricultural Research, v.24, n. 1, p.161-168, 1973.

BRYAN, R. P. The effect of dung beetles, Onthophagus gazella, on the ecology of the infective larvae of gastrointestinal nematodes of cattle. Australian Journal of Agricultural Research, v.27, n.4, p.567-574, 1976.

CALAFIORI, M. H. Influência do Dichotomius anaglypticus (Mannerheim, 1829) (Coleoptera: Scarabaeidae) na fertilização do solo e no desenvolvimento do milho (Zea mays L.). Piracicaba, 1979. 87p. Dissertação (Mestrado) - Escola Superior de Agricultura "Luiz de Queiroz", Universidade de São Paulo. 
CALAFIORI, M. H.; ALVES, S. B. Influência de casais do Dichotomius anaglypticus (Mannerheim, 1829) (Coleoptera: Scarabaeidae) na fertilização do solo e no desenvolvimento do milho (Zea mays L.). Ecossistema, v.5, n. 1, p.8-16, 1980.

CAMERIK, A. M.; COETZEE, S. H. Phoretic females of two new species of the genus Pediculaster (Acari: Pygmephoridae) from cattle dung in South Africa. International Journal of Acarology, v.24, n. 1, p.21-31, 1998.

CHRISTIE, J. E. A new species of Alliphis (Mesostigmata: Eviphididae) from Britain. Acarologia, v.24, n.3, p.231-242, 1983.

CICOLANI, B. Sulla biologia, ecologia e morfologia di Macrocheles vernalis (Berl.) (Acarina: Mesostigmata). Redia, v.68, p.441-457, 1980.

COSTA, M. Notes on macrochelids associated with manure and coprid beetles in Israel. I. Macrocheles robustulus (Berlese, 1904). Development and biology. Acarologia, v.8, n. 4, p. $532-548,1966$.

COSTA, M. Notes on macrochelids associated with manure and coprid beetles in Israel. II. Three new species of the Macrocheles pisentii complex, with notes on their biology. Acarologia, v. 9, n. 2, p. 304-329, 1967.

COSTA, M. The association between mesostigmatic mites and coprid beetles. Acarologia, v.11, n.3, p.411-428, 1969.

CUDMORE, W. W.; WHITAKER Jr., J. O.; SMILEY, R. L. Mites of the genus Pygmephorus in Oregon. Acarologia, v.28, n.4, p.331-332, 1987. 
DASTYCH, H.; RACK, G. Some notes on morphology of mites of the genus Pygmephorus (Acari: Heterostigmata). Acarologia, v.34, n.2, p.131-141, 1993.

DASTYCH, H.; RACK, G. Spatulaphorus Rack gen. $\mathrm{n}$. and three new species of pygmephorid mites associated with scarab beetles in Botswana and Vietnam (Acari: Heterostigmata). Mitt. Hamb. Zool. Mus. Inst., n.90, p.265-284, 1993b.

DELFINADO, M. D.; BAKER, E. W. New species of Scutacaridae (Acarina) associated with insects. Acarologia, v.18, n.2, p.264-301, 1976.

DOUBE, B. M.; GLLLER, P. S.; MEOLA, F. Dung burial strategies in some South African Coprini and Onitini dung beetles (Scarabaeidae: Scarabaeinae). Ecological Entomology, v.13, n.3, p.251-161, 1988.

D'OLSOUFIEFF, G. Les phaneides (Coleoptera-Lamellicornia) família Scarabaeidae Tr. Coprini. Insecta, v.13, n.145/156, p.1-172, 1924.

EBERMANN, E. To the knowledge of the tarsonemid fauna of italian islands (Acari: Microdispidae, Scutacaridae). Redia, v.69, p.469-480, 1986 .

EBERMANN, E. Zur kenntnis der scutacariden südamerikas (Acari, Tarsonemina). Adrias, v. 5, p.5-14, 1986b.

EBERMANN, E. Imparipes (Imparipes) pselaphidorum n, sp., a new scutacarid species phoretic upon african beetles (Acari: Scutacaridae; Coleoptera, Pselaphidae). Acarologia, v.29, n.1, p.35-42, 1988. 
EBERMANN, E.; PALACIOS-VARGAS, J.G. Imparipes (Imparipes) tocatlphilus $\mathrm{n}$. sp. (Acari, Tarsonemina, Scutacaridae) from Mexico and Brazil: first record of ricinuleids as phoresy hosts for scutacarid mites. Acarologia, v.29, n.4, p.347-354, 1988.

EBERMANN, E. Taxonomic consequences of the polymorphism found in scutacarids (Acari, Scutacaridae). Entomologische Mitteilungen aus dem Zoologischen Museum Hamburg., v.10, n.139/140, p.29-42, 1990.

EBERMANN, E. Thanatosis or feigning death in mites of the family Scutacaridae. In: R. Schuster; P. W. Murphy (eds.): The Acari. Reproduction, Development and LifeHistory Strategies. Chapman \& Hall, London: 1991a; p.399-401.

EBERMANN, E. Records of polymorphism in the mite family Scutacaridae (Acari, Tarsonemina). Acarologia, v.32, n.2, p.119-138, 1991b.

EBERMANN, E. Pygmodispus (Allodispus) pavidus n.sp. (Acari, Tarsonemina, Scutacaridae), eine neue terrestrische Milbenart aus dem Stadtzentrum von Graz, Österreich. Mitteilungen. Naturwiss. Ver. Steiermark, p.127-133, 1997a.

EBERMANN, E. Redescription of Pygmodispus (Allodispus) mancus (Acari, Tarsonemina, Scutacaridae), a mite species from Australia. Entomologische Mitteilungen aus dem Zoologischen Museum Hamburg., v.12, n.156, p.197-203, 1997b.

EBERMANN, E. New species and records of Scutacaridae (Acari: Tarsonemina) from Mexico and Central America. International Journal of Acarology, v.23, n.4, p.249$260,1997 \mathrm{c}$. 
EBERMANN, E. Imparipes (Sporichneuthes nov. subgen.), a remarkable new taxon in the mite family Scutacaridae (Acari, Heterostigmata). In: EBERMANN, E. (Ed.) Arthropod Biology: Contributions to Morphology, Ecology and Systematics. 1998. cap. 14, p.179-214. Biosystematics and Ecology Series.

ELZINGA, R. J. Six new species of Trichocylliba (Acari: Uropodina) associated with army ants. Acarologia, v.36, n.2, p.107-115, 1995.

FAIN, A.; CHMIELEWSKI, W. The phoretic hypopi of two acarid mites described from ants' nest: Tyrophagus formicetorum Volgin, 1948 and Lasioacarus nidicolus Kadzhaja and Sevastianov, 1967. Acarologia, v.28, n.1, p.53-61, 1987.

FAIN, A.; NOTI, M. I.; DUFRÊNE, M. Observations on the mites (Acari) associated with Carabidae (Coleoptera) in Belgium. I. Annotated list of the species. International Journal of Acarology, v.21, n.2, p.107-122, $1995 \mathrm{a}$.

FAIN, A.; HURST, G. D. D., TWEDDLE, J. C. et. al. Description and observations of two new species of Hemisarcoptidae from deutonymphs phoretic on Coccinellidae (Coleoptera) in britain. International Journal of Acarology, v.21, n.2, p.99-106, $1995 b$.

FARISH, D. J.; AXTELL, R. D. Phoresy redefined and examined in Macrocheles muscaedomesticae (Acarina: Macrochelidae). Acarologia, v. 13, n.1, p.16-29, 1971.

FERREIRA, A. M. R. M.; GALILE0, M. H. M. Revisão taxonômica do gênero Pedaridium Harold, 1868 (Coleoptera, Scarabaeidae, Scarabaeinae, Coprini). Iheringia, v.74, p.3-69, 1993. 
FILIPPONI, A.; PEGAZZANO, F. Contributo alla conoscenza del genere Holostaspella Berlese, 1903 (Acari: Mesostigmata: Macrochelidae). Redia, v.50, p.219-259, 1967.

FINCHER, G. T. Sustained-release bolus for horn fly (Diptera: Muscidae) control: effects of methoprene ans diflubenzuron on some nontarget species. Environmental Entomology, v.20, n.1, p.77-82, 1991.

FLECHTMANN, C. H. W. Ácaros de importância agrícola. São Paulo, Livraria Nobel. 1989, 189p.

FLECHTMANN, C. H. W. Ácaros associados à abelha milifera. In: CONGRESSO BRASILEIRO DE APICULTURA, 5. CONGRESSO LATINO-IBEROAMERICANO DE APICULTURA, 3. Viçosa, MG, 1980. Anais. Viçosa: ed, 1980. p.189-202.

FLECHTMANN, C. H. W.; ALVES, S. B. Observações sobre ácaros (Acari) associados a besouros coprófagos (Coleoptera, Scarabaeidae). In: CONGRESSO BRASILEIRO DE ENTOMOLOGIA, 3. Maceió, Al, 1976. Resumos. Maceió/Al 1976. p.131.

FLECHTMANN, C. A. H.; RODRIGUES, S. R.; SENO, M. C. Z. Controle biológico da mosca-dos-chifres (Haematobia irritans irritans) em Selvíria, Mato Grosso do Sul. 1. Metodologia de estudo e seleção de fauna fimícola de insetos. Revista Brasileira de Entomologia, v.39, n.1, p.1-11, 1995a.

FLECHTMANN, C. A. H.; RODRIGUES, S. R.; ARAÚJO, S. D. et. al. Levantamento de insetos fimícolas em Ilha Solteira, São Paulo, Brasil. Revista Brasileira de Entomologia, v.39, n.1, p.115-120, 1995 b. 
FLEChTMANN, C. A. H.; RODRIGUES, S. R.; SENO, M. C. Z. Controle biológico da mosca-dos-chifres (Haematobia irritans irritans) em Selvíria Mato Grosso do Sul. 3. Levantamento de espécies fimícolas associadas à mosca. Revista Brasileira de Entomologia, v.39, n.2, p.249-258, 1995c.

FLECHTMANN, C. A. H.; RODRIGUES, S. R.; COUTO, H. T. Z. Controle biológico da mosca-dos-chifres (Haematobia irritans irritans) em Selvíria, Mato Grosso do Sul. 4. Comparação entre métodos de coleta de besouros coprófagos (Scarabaeidae). Revista Brasileira de Entomologia, v.39, n.2, p.259-276, 1995d.

FLECHTMANN, C. A. H.; RODRIGUES, S. R. Insetos fimícolas associados a fezes bovinas em Jaraguá do Sul/SC. 1. Besouros coprófagos (Coleoptera, Scarabaeidae). Revista Brasileira de Entomologia, v.39, n.2, p.303-309, 1995.

FURNISS, M. M.; HUNGERFORD, R. D.; WICKER, E. F. Insects and mites associated with western white pine blister rust cankers in Idaho. The Canadian Entomologist, v.104, p. 1713-1715, 1972.

GALLO, D.; NAKANO, O.; SILVEIRA NETO, S. et. al. 1988. Manual de Entomologia Agrícola. São Paulo: Ed. Agr. Ceres, 1988. 649p.

GAO, J. R.; ZOU, P.; QIN, R. A new species of the genus Siteroptes (Acari: Pygmephoroidea) from Xizang, the people's republic of China. Acarologia, v.38, n.2, p. 153-159, 1997. 
GEDEN, C. J.; AXTELL, R. C. Predation by Carcinops pumilio (Coleoptera: Histeridae) and Macrocheles muscaedomesticae (Acarina: Macrochelidae) on the house fly (Diptera: Muscidae): Functional response, effects of temperature, and availability of alternative prey. Environmental Entomology, v.17, n.4, p.739-744, 1988.

GEDEN, C. J.; STINNER, R. E.; KRAMER, D. A. et. al. A simulation model for Macrocheles muscaedomesticae (Acari: Macrochelidae) population dynamics and rates of predation on immature house flies (Diptera: Muscidae). Environmental Entomology, v.19, n.3, p.578-586, 1990.

GORDH, G.; WILLS, L. Anatomical notes on Uropoda sp., a phoretic mite infesting dung-inhabiting beetles in southern California (Acari: Uropodidae; Coleoptera: Tenebrionidae, Histeridae). Pan-Pacific Entomologist, v.65, n.4, p.410-413, 1989.

HALFFTER, G.; MATTHEWS, E. G. The natural history of dung beetles. A supplement on associated biota. Revista Latino-americana de Microbiologia, v.13, p.147-164, 1971.

HALLIDAY, R. B.; HOLM, E. Mites of the family Macrochelidae as predators of two species of dung-breeding pest flies. Entomophaga, v.32, n.3, p.333-338, 1987.

HO, T. M. Phoretic association between Macrocheles muscaedomesticae (Acari: Macrochelidae) and flies inhabiting poultry manure in Peninsular Malaysia. Experimental \& Applied Acarology, v.10, p.61-68, 1990. 
HONER, M. R.; BIANCHIN, I.; GOMES, A. Desenvolvimento de um programa integrado de controle dos nematódeos e a mosca-dos-chifres na região dos cerrados. Fase 1. Campo Grande, EMBRAPA-CNPGC, 1987. 4p. (EMBRAPA-CNPGC. Pesquisa em Andamento, 36).

HOSCHELE, W.; TANIGOSHI, L. K. Pyemotes tritici (Acari; Pyemotidae), a potential biological control agente of Anagasta kuehniella (Lepidoptera: Pyralidae). Experimental \& Applied Acarology, v.17, p.781-792, 1993.

HOUCK, M. A.; O'CONNOR, B. M. Ecological and evolutionary significance of phoresy in the astigmata. Annual Revue Entomologie, v.36, p.611-636, 1991.

HOY, C. W.; GLENISTER, C. S. Releasing Amblyseius spp. (Acarina: Phytoseiidae) to control Thrips tabaci (Thysanoptera: Thripidae) on cabbage. Entomophaga, v.36, n.4, p.561-573, 1991.

HUSBAND, R. W. A revision of the genus Tarsopolipus (Acari: Podapolipidae), parasites of african and european Scarabaeidaee, with descripition of three new species. International Journal of Acarology, v.15, n.3, p.163-178, 1989.

HUSBAND, R. W.; BAKER, A. A new species of Podapolipus (Acari: Podapolipidae) ectoparasitic on Alphitobius laevigatus (Tenebrionidae) from Trindad. International Journal of Acarology, v.18, n.2, p.83-87, 1992.

HUSBAND, R. W.; KUROSA, K. Scarabapolipus uchikawai n. gn., n. sp. (Acari: Podapolipidae) from Protaetia orientalis submarmorea (Coleoptera: Scarabaeidae). International Journal of Acarology, v. 19, n. 1, p.57-62, 1993. 
HUSBAND, R. W.; KUROSA, K. Four new species of Scarabapolipus (Acari: Podapolipidae) Ectoparasites of Scarabaeidae (Coleoptera) from the Western Pacific Region. Annals of the Entomological Society of America, v.87, n.4, p.424-435, 1994.

JESSOP, L. An identification guide to Eurysternine dung beetles (Coleoptera, Scarabaeidae). Journal of Natural History, v. 19, n.6, p.1087-1111, 1985.

KALISZ, P. J.; STONE, E. L. Soil mixing by scarab beetles and pochet gophers in North Central Florida. Soil Science Society of America Journal, v.48, n.1, p.169-172, 1984.

KALISZEWSKI, M.; RACK, G. Description of female and male of Pygmephorus sylvilagus n.sp. and male of Pygmephorus erlangensis Krczal, 1959 (Acari, Pygmephoridae). Entomol. Mitt. Zool. Mus. Hamburg., v.8, n.123, p.45-60, 1985.

KALISZEWSKI, M.; RACK, G. A systematic study of the mite Microdispus (Premicrodispus) lambi (Krczal, 1964) (Acari: Pygmephoroidea), a mushroom pest in Australia. Mitt. Hamb. Zool. Mus. Inst., n.83, p.231-241, 1986.

KALISZEWSKI, M. Diroptes gen. n. (Acari, Pygmephoroidae) with a key to the species. Entomol. Mitt. Zool. Mus. Hamburg., v.9, n. 132, p.115-122, 1988a.

KALISZEWSKI, M. Pseudobakerdania gen. n. (Acari, Pygmephoroidea) with the description of two new species and some remarks on the phylogenetic position of the genus. Entomol. Mitt. Zool. Mus. Hamburg., v.9, n. 132, p.123-134, 1988b.

KLEIN, B. C. Effects of forest fragmentation on dung and carrion beetle communities in central Amazonia. Ecology, v.70, n.6, p.1715-1725, 1989. 
KOLLER, W. W., GOMES, A., RODRIGUES, S. R. et. al. Besouros coprófagos (Coleoptera: Scarabaeidae) coletados em Campo Grande, MS, Brasil. Anais da Sociedade Entomológica do Brasil, v.28, n.3, p.403-412, 1999.

KRANTZ, G. W. A manual of acarology. Corvallis, Oregon. Oregon State University Book Stores, 1975. 335p.

KRANTZ, G. W. A manual of Acarology. Corvallis, Oregon. Oregon State University Book Stores, 1978. 509p.

KRANTZ, G. W. A review of the genus Neopodocinum Oudemans, 1902 (Acarina: Macrochelidae). Acarologia, v.2, n.7, p.139-226, 1965.

KRANTZ, G. W. A review of tje genus Holocelaeno Berlese, 1910 (Acarina: Macrochelidae). Acarologia, v.9, p.1-89, 1967. supplementum.

KRANTZ, G. W.; MELLOTT, J. L. Studies on phoretic specificity in Macrocheles mycotrupetes and M. peltotrupetes Krantz and Mellott (Acari: Macrochelidae), associates of Geotrupine Scarabaeidae. Acarologia, v.14, n.3, p.317-344, 1972.

KRANTZ, G. W. Two new glaber group species of Macrocheles (Acari: Macrochelidae) from Southern Africa. International Journal of Acarology, v.7, p.3-16, 1981.

KRANTZ, G. W. Three new species of Macrocheles (Acari: Gamasida: Macrochelidae) associated with 3-toed sloths, Bradypus spp. (Edentata: Bradypodidae), in Brazil and Surinam. Acarologia, v.24, n.1, p.3-12, 1983. 
KRANTZ, W. G.; WHITAKER Jr., J. O. Mites of the genus Macrocheles (Acari: Macrochelidae) associated with small mammals in north america. Acarologia, v.29, n.3, p.225-259, 1988.

KRANTZ, G. W. Nature of the association between pisentii-group mites (Acari: Macrochelidae: Macrocheles) and dung beetles of the genus Scarabaeus (Coleoptera: Scarabaeidae) in southern France. Acarologia, v.32, n.1, p.3-11, 1991.

KRANTZ, G. W.; ROYCE, L. A. Descriptions of the immature stases of Macrocheles mycotrupetes Krantz and Mellott (Acari: Macrochelidae), with remarks on from, function, and phoresy. Acarologia, v.33, n.4, p.305-311, 1992.

KRANTZ, G. W.; ROYCE, L. A. Observations on the biology and behavior of Macrocheles mycotrupetes Krantz \& Mellott (Acari: Macrochelidae). International Journal of Acarology, v.20, n.2, p.115-121, 1994.

KRANTZ, G. W. Reflections on the biology, morphology and ecology of the Macrochelidae. Experimental \& Applied Acarology, v.22, p.125-137, 1998.

LANGE, R. B. Ensaio da zoogeografia dos Scarabaeidae no Paraná com algumas notas eto-ecológicas. Arquivos do Museo Paranaense, v.6, p.305-315, 1947.

LINDQUIST, E. E. Authorship of the family-group names Tarsonemidae and Podapolipidae and priority of Scutacaridae over Pygmephoridae (Acari: Heterostigmata). Acarologia, v.26, n.2, p.141-145, 1985.

LINK, D. Abundância relativa e fenologia de alguns Scarabaeoidea fototáticos, na zona de campos de Santa Maria, RS. (Coleoptera). Curitiba, 1976. 79p. Tese (Doutorado) Universidade Federal do Paraná. 
LIZASO, N. M.; MENDES, M. C.; SANTOS, A. M. M. Duas novas espécies de Macrocheles (Acarina, Macrochelidae) da região neotropical coletadas em esterco de aves poedeiras em granjas industriais. Revista Brasileira de Entomologia, v.36, n.3, p.597-601, 1992.

LIZASO, N. M.; MENDES, M. C. Novo gênero e nova espécie de Macrochelidae (Acarina): Mesocheles lordosos gen. n., sp. n., de esterco bovino. Revista Brasileira de Entomologia, v.38, n.2, p.467-469, 1994.

LOBO, J. M.; MARTIN-PIERA, F.; VEIGA, C. M. Las trampas pitfall con cebo, sus possibilidades en el estudio de las comunidades coprófagas de Scarabaeoidea (Col.). I. Características determinantes de su capacidad de captura. Revue D'ecologie et de Biologie du Sol, v.25, n.1, p.77-100, 1988.

LOUZADA, J. N. C.; LOPES, F. S. A comunidade de Scarabaeidae copro-necrófagos (Coleoptera) de um fragmento de Mata Atlântica. Revista Brasileira de Entomologia, v.41, n. 1, p.117-121, 1997.

LUEDERWALDT, H. As espécies brasileira do gênero Pinotus (Coleoptera Lamellicomidae - Coprini), com algumas considerações também sobre outras espécies. Revista do Museu Paulista, v.16, p.603-779, 1929.

LUEDERWALDT, H. O gênero Ontherus (Coleop.) (Lamellic - Coprid.- Pinot.) com uma chave, para determinação dos pinotides americanos. Revista do Museu Paulista, v.17, p.363-422, 1931.

LUNDQVIST, L.; MICHERDZINSKI, W. Neubeschreibung von Parasitus talparum Oudemans, 1913 (Acari: Mesostigmata: Parasitidae). Entomology Scandinavian, v.6, p.71-78, 1975 . 
MAHUNKA, S.; ROHDE, Jr., C. J. A new scutacarid and some pyemotid mites from Iran. Acarologia, v.12, n. 1, p.103-105, 1970.

MARIATEGUI, P.G.; SPEICYS, C. Búsqueda de artrópodos biocontroladores de Haematobia irritans (linneus, 1758). (Diptera: Muscidae). In: CONGRESSO BRASILEIRO DE ENTOMOLOGIA, 16, Salvador/BA, 1997. Resumos. 1997. p. 140 .

MASAN, P. The eviphidid mites (Acarina: Mesostigmata: Eviphididae) associated with scarabaeid on carrion beetles (Coleoptera: Scarabaeidae, Silphidae) in central Europe. Acarologia, v.35, n.1, p.3-19, 1994.

MATTOS, M. R. Macrochelídeos associados a fezes acumuladas em granja de aves poedeiras do município de montemor, estado de São Paulo: levantamento, taxonomia e estudos populacionais (Acari, Gamasida: Macrochelidae). Campinas, 1992. 76p. Dissertação (Mestrado) - Universidade Estadual de Campinas.

MCNEIL, J. N.; TREAT, A. E. Mites associated with the true armyworm, Pseudaletia unipuncta (Lepdoptera: Noctuidae), in the Azores. International Journal of Acarology, v.18, n.2, p.143-144, 1992.

MENDES, M.C. \& LIZASO, N.M. Macrocheles novaodessensis, sp. n. e Macrocheles roquensis, sp. n. coletados em esterco bovino na região neotropical (Acarina, Macrochelidae). Revista Brasileira de Zoologia, v.9, n.3/4, p.357-361, 1992.

METWALI, S. H. Survey on the family Scutacaridae (Acari) in Egypt. II. Acarologia, v.25, n.3, p.241-248, 1984. 
MOMEN, F. M.; CURRY, J. P. Four new species of scutacarid mites (Acarina: Prostigmata) from Ireland. Acarologia, v.28, n.2, p.129-135, 1987.

MOMEN, F. M.; CURRY, J. P. Four new species of the genus Imparipes (Acarina: Tarsonemina: Scutacaridae) from Ireland. Acarologia, v.29, n. 1, p.43-50, 1988.

MOMEN, F. M.; EL-BAGOURY, M. E. Five new species of scutacarid mites (Acari: Tarsonemina) from Egypt. Acarologia, v.30, n. 1, p.41-50, 1989.

MOSER, J. C.; ROTON, L. M. Mites associated with southern pine bark beetles in Allen Parish, Lousiana. The Canadian Entomologist, v.103, p.1775-1798, 1971.

MOSER, J. C.; CROSS, E. A. Phoretomorph: A new phoretic phase unique to the Pyemotidae (Acarina: Tarsonemoidea). Annals of the Entomological Society of America, v.68, n.5, p.820-822, 1975.

NASKRECKI, P.; COLWELL, R. K. New genus and two new species of Melicharini from Venezuela (Acari: Mesostigmata: Ascidae). Annals of the Entomological Society of America, v.88, n.3, p.284-293, 1995.

NAWAR, M. S. Macrocheles zaheri, a new species in the glaber group (Acari: Macrochelidae) from Egypt. Acarologia, v.36, n.2, p.97-100, 1995.

OLIVEIRA, G. P.; RODRIGUES, S. R.; GROMICK, M. B. Espécies de besouros fimícolas ocorrentes em áreas de pastagens em São Carlos, SP. In: CONGRESSO BRASILEIRO DE MEDICINA VETERINÁRIA, 24, Goiânia.GO. 1996. Anais. Goiânia, GO: 1996. p.153-154. 
OLIVER Jr., J. H.; KRANTZ, G. W. Macrocheles rodriguezi, a new species of mite from Kansas (Acarina: Macrochelidae) with notes on its life cycle and behavior. Acarologia, v.5, n.4, p.519-525, 1963.

OLYNYK, J. E.; FREITAG, R. Some phoretic associations of ground beetles (Coleoptera: Carabidae) and mites (Acarina). Canadian Entomologist, v.111, p.333-335, 1979.

PAULIAN, R. Contribution a l'étude des canthonides américains (Coleopt. Lamellic.). Annales de la Sociéte Entomologique de France, v.108, p.1-40, 1939.

PEREIRA, C.; CASTRO, M. P. Forese e partenogênese arrenótoca em Macrocheles muscaedomesticae (Scopoli) (Acarina: Macrochelidae) e sua significação ecológica. Arquivos dos Instituto Biológico, v. 18, n.4, p.71-89, 1947.

PESSOA, S. B. Contribuição para o conhecimento das espécies brasileiras do gênero Phanaeus (Col. Scarabaeidae). Annaes da Faculdade de Medicina de São Paulo, v.10, n.3, p.279-314, 1934.

PESSOA, S. B. Notas sobre o gênero Taurocopris, com a descripção de uma espécie nova (Col. Scarabaeidae). Annaes da Faculdade de Medicina de São Paulo, v.11, n.1, p.33-35, 1935.

POLAK, M. Ectoparasitic effects on host survival and reproduction: the DrosophilaMacrocheles association. Ecology, v.77, n.5, p.1379-1389, 1996.

POPRAWSKI, T. J.; YULE, W. N. Acari associated with Phyllophaga anxia (Leconte) (Coleoptera: Scarabaeidae) in Southern Quebec and Eastern Ontario. Canadian Entomologist, v.124, p.397-403, 1992. 
PUGH, P. J. A.; KING, P. E.; FORDY, M. R. Larvae of Trombidium (Trombidium) poriceps (Oudemans) (Trombidiidae: Prostigmata: Acarina) parasitic on Chersodromia speculifera Walker (Empididae: Diptera: Hexapoda). Acarologia, v.32, n.1, p.23-27, 1991 .

RACK, G.; KALISZEWSKI, M. Zwei neue arten der gattung Bakerdania Sasa, 1961 (Acari, Prostigmata, Pygmephoroidea) aus Belgien. Entomol. Mitt. Zool. Mus. Hamburg., v. 8, n. 125, p. 145-157, 1985.

RAMARAJU, K.; MOHANASUNDARAM, M. New species of Podapolipus, Podapolipoides and Tarsopolipus (Acari: Podapolipidae) from south India. International Journal of Acarology, v.22, n. 1, p.33-41, 1996.

RICHARDS, K. W.; RICHARDS, L. A. A new species of Macrocheles (Acarina: Macrochelidae) found in bumble bee nests (Hymenoptera: Apidae). The Canadian Entomologist, v.109, p.711-719, 1977.

RIDSDILL-SMITH, T. J. Survival and reproduction of Musca vetustissima Walker (Diptera: Muscidae) and a scarabaeine dung beetle in dung of cattle treated with avermectin b1. Journal of the Australian Entomological Society, v.27, n.3, p.175$178,1988$.

RODRIGUES, L. R. A. Aspectos comportamentais dos besouros coprófagos em pastagens. In: ENCONTRO PAULISTA DE ETOLOGIA, 3. Ribeirão Preto, 1985. Anais. Ribeirão Preto: AZESP, 1985. p.95-103.

RODRIGUES, S. R.; MARCHINI, L. C. Besouros coprófagos (Coleoptera, Scarabaeidae) coletados em Piracicaba, SP. Scientia Agricola, v.55, n.1, p.53-58, 1998. 
RODRIGUES, S. R.; FLECHTMANN, C. A. H. Besouros coprófagos (Coleoptera, Scarabaeidae) em Pereira Barreto/SP. In: CONGRESSO BRASILEIRO DE ENTOMOLOGIA, 15, Caxambu, MG, 1995. Anais. Caxambu, MG: SEB, 1995, p.580.

ROTH, J. P.; MACQUEEN, A.; BAY, D. E. Predation by the introduced phoretic mite, Macrocheles peregrinus (Acarina: Macrochelidae), on the buffalo fly, Haematobia irritans exigua (Diptera: Muscidae), in Australia. Environmental Entomology, v.17, n.3, p.603-607, 1988.

ROYCE, L. A.; KRANTZ, G. W. Observations on pollen processing by Pneumolaelaps longnalis (Acari: Laelapidae), a mite associate of bumblebees. Experimental \& Applied Acarology, v.7, p.161-165, 1989.

RUBINK, W. L.; DELFINADO-BAKER, M.; WILSON, W. T. et all. A phoretic uropodid mite associated with honey bee swarms of northeastern Mexico. International Journal of Acarology, v. 17, n.4, p.259-263, 1991.

RUIZ DIAS, M. A.; MARCHINI, L. C.; RODRIGUES, S. R. et all. Horário de atividade de besouros coprófagos (Coleoptera, Scarabaeidae) em área de pastagem e mata. In: MEMÓRIAS DA IV REUNIÃO LATINO-AMERICANA DE SCARABAEOIDOLOGIA. 4, Viçosa, MG, 1999. Resumos. Viçosa, MG, 1999. p.68-69.

SAMSINAK, K.; DANIEL, M. Five new species of mesostigmatic mites from geotrupes beetles collected in the Himalayan region of Nepal (Acari: Mesostigmata). International Journal of Acarology, v.4, n.2, p.91-100, 1978. 
SAMSINAK, K. Mites on flies of the family Sphaeroceridae. II. Acarologia, v.30, n.2, p.85-105, 1989.

SAVULKINA, M. M. Systematics, ecology, and distribution of mites of the family Pygmephoridae Cross, 1965 (Acari, Trombidiformes). Transl. of Entomol. Oborz. v. 60, p.434-450, 1981.

SCHELVIS, J. Predatory mites (Acari; Gamasida) in excrements of five domestic animal species. Pedobiologia, v.38, n.1, p.72-80, 1994.

SCHOUSBOE, C. Deutonymphs of Parasitellus phoretic on danish bumblebees (Parasitidae, Mesostigmata; Apidae, Hymenoptera). Acarologia, v.28, n.1, p.37-41, 1987.

SILVEIRA NETO, S.; NAKANO, O.; BARBIN, D. et all. Manual de Ecologia dos insetos. São Paulo: Ceres, 1976. 419p.

SMILEY, R. L. Taxonomic studies of Pygmephorus species from the western hemisphere, with a key to females and an overview of the current problems for classification (Acari: Pyemotidae and Pygmephoridae). International Journal of Acarology, v.4, n.2, p.125-160, 1978.

SMILEY, R. L.; SHITAKER, Jr., J. O. Key to new and old world Pygmephorus species and descriptions of six new species (Acari: Pygmephoridae). International Journal of Acarology, v. 10, n.2, p.59-73, 1984.

STEPHEN, F. M.; KINN, D. N. Spatial distribution of mite associates of within-tree populations of Dendroctonus frontalis Zimm. Environmental Entomology, v.9, n.5, p.713-715, 1980. 
STUMPF, I. V. K. Estudo da fauna de escarabeídeos em Mandirituba, Paraná, Brasil. Acta Biológica Paranaense, v.15, n.1/4, p.123-153, 1986.

TAKAKU, G. S. New species of the genus Holostaspella (Acari, Macrochelidae) from northern Japan. Acarologia, v.35, n.4, p.295-304, 1994.

TAKAKU, G. Redescription of Eviphis cultratellus (Berlese) (Acari: Eviphididae). Acarologia, v.38, n.4, p.345-355, 1997.

VAZ-DE-MELLO, F. Z. Scarabaeidae s. str. (Coleoptera: Scarabaeoidea) de um fragmento de floresta amazônica no estado do Acre, Brasil. 1. Taxocenose. Anais da Sociedade Entomológica do Brasil, v.28, n.3, p.447-453, 1999.

VIANA, B. F. Ocorrência do ácaro Acarapis woodi (Renie) em abelhas africanizadas no Estado da Bahia. In: CONGRESSO BRASLLEIRO DE APICULTURA, 10., Pousada do Rio Quente, Goiás. 1994. Anais. Pousada do Rio Quente: Associação dos Apicultores do Estado de Goiás. 1994. p.347.

WALLACE, M. M. H.; HOLM, E. The seasonal abundance of phoretic predatory mites associated with dung beetles in south eastern Australia (Acari: Macrochelidae, Parasitidae). International Journal of Acarology, v.11, n.3, p. 183-189, 1985.

WALLACE, M. M. H. Some macrochelid mites (Acari: Macrochelidae) associated with australian dung beetles (Coleoptera: Scarabaeidae). Acarologia, v.27, n. 1, p.3-15, 1986. 
WALTER, D. E.; KRANTZ, G. W. A review of glaber-like species with reduced sclerotization and ventral ornamentation: the scutatus subgroup (Acari: Macrochelidae: Macrocheles). International Journal of Acarologia, v. 18, n.3, p.241-249, 1992.

WENDT, F. R.; OLOMSKI, R.; LEIMAN, J. et all. Parasitism, life cycle and phenology of Leptus trimaculatus (Hermann, 1804) (Acari: Parasitengonae: Erythraeidae) including a description of the larva. Acarologia, v.33, n.1, p.55-68, 1992.

WHITAKER Jr., J. O.; FRENCH, T. W.; SMILEY, R. L. Notes on host relationships and host specificity of mites of the genus Pygmephorus (Acari: Pygmephoridae) on insectivores and rodents from mount carleton provincial park, new brunswick. International Journal of Acarology, v.8, n.4, p.233-235, 1982.

WISE, G. U.; HENNESSEY, M. K.; AXTELL, R. C. A new species of manureinhabiting mite in the genus Poecilochirus (Acari: Mesostigmata: Parasitidae) predacious on house fly eggs and larvae. Annals of the Entomological Society of America, v.81, n.2, p.209-224, 1988.

WISNIEWSKI, J.; HIRSCHMANN, W. Neue mit Uropoda heliocopridis (Oudemans, 1901) (Acarina, Uropodina) verwandte arten aus Asien, Amerika und Europa. Acarologia, v.37, n.4, p.269-274, 1996.

WRIGHT, E. M.; CHAMBERS, R. J. The biology of the predatory mite Hypoaspis miles (Acari: Laelapidae), a potential biological control agent of Bradysia paupera (Dipt.: Sciaridae). Entomophaga, v.39, n.2, p.225-235, 1994. 